NBER WORKING PAPER SERIES

\title{
PHOENIX MIRACLES IN EMERGING MARKETS: RECOVERING WITHOUT CREDIT FROM SYSTEMIC FINANCIAL CRISES
}

\author{
Guillermo A. Calvo \\ Alejandro Izquierdo \\ Ernesto Talvi \\ Working Paper 12101 \\ http://www.nber.org/papers/w12101
NATIONAL BUREAU OF ECONOMIC RESEARCH
1050 Massachusetts Avenue
Cambridge, MA 02138
March 2006

We are very grateful to Fernando Alvarez, Barry Eichengreen, Marcus Miller, Andy Neumeyer, Maury Obstfeld, Ned Phelps, and participants of the VIII Workshop in International Economics and Finance held at UTDT, Buenos Aires, Argentina, and Columbia University for very useful comments on a previous version of the paper. Moreover, we would like to thank IDB research assistants Rudy Loo-Kung and Gonzalo Llosa, and CERES research assistants Diego Pereira, Ignacio Munyo, Inés Levin and Virginia Olivella. Without their help this paper could not have seen the light of day. The views expressed herein are those of the author(s) and do not necessarily reflect the views of the National Bureau of Economic Research.

(C2006 by Guillermo A. Calvo, Alejandro Izquierdo, and Ernesto Talvi. All rights reserved. Short sections of text, not to exceed two paragraphs, may be quoted without explicit permission provided that full credit, including (C) notice, is given to the source. 
Phoenix Miracles in Emerging Markets: Recovering without Credit from Systemic Financial Crises Guillermo A. Calvo, Alejandro Izquierdo, and Ernesto Talvi

NBER Working Paper No. 12101

March 2006

JEL No. F31, F32, F34, F41

\begin{abstract}
Using a sample of emerging markets that are integrated into global bond markets, we analyze the collapse and recovery phase of output collapses that coincide with systemic sudden stops, defined as periods of skyrocketing aggregate bond spreads and large capital flow reversals. Our findings indicate the presence of a very similar pattern across different episodes: output recovers with virtually no recovery in either domestic or foreign credit, a phenomenon that we call Phoenix Miracle, where output "rises from its ashes", suggesting that firms go through a process of financial engineering to restore liquidity outside the formal credit markets. Moreover, we show that the US Great Depression could be catalogued as a Phoenix Miracle. However, in contrast to the US Great Depression, EM output collapses occur in a context of accelerating price inflation and falling real wages, casting doubts on price deflation and nominal wage rigidity as key elements in explaining output collapse, and suggesting that financial factors are prominent for understanding these collapses.
\end{abstract}

Guillermo A. Calvo

Inter-American Development Bank

1300 New York Ave., N.W.

Washington, DC 20577

and NBER

gcalvo@iadb.org

Alejandro Izquierdo

Inter-American Development Bank

1300 New York Ave., N.W.

Washington, DC 20577

alejandroi@iadb.org

Ernesto Talvi

CERES

Antonio Costa 3476

11300 Montevideo

Uruguay

etalvi@ceres-uy.org 


\section{Introduction}

In the last quarter century, the Emerging Market (EM) landscape has been plagued with financial crises of severe magnitude. Many of these crises occurred during periods of Systemic Sudden Stop (henceforth, 3S), i.e., periods of capital inflow collapse, or Sudden Stop, and skyrocketing EM aggregate bond spreads that affected a wide range of EM countries at approximately the same time and, thus, had a systemic component. In several instances, financial crises coincided with severe output losses and dire social consequences.

Turmoil in EM world capital markets, coupled with country-specific vulnerabilities, such as the level of domestic liability dollarization (DLD), i.e., foreignexchange denominated debt contracts in the domestic capital market, ${ }^{1}$ and the size of the supply of tradable goods, appear to be key in explaining recent financial crises in EMs involving sudden interruptions in capital flows. ${ }^{2}$ Shocks at the heart of capital markets, or "incipient" Sudden Stops in the Calvo, Izquierdo and Loo-Kung (2005) lexicon, have typically been a triggering factor behind these crises. Contagion, for example - - be it because countries are treated as part of a particular asset class, borrow from the same set of banks, are part of the same set of investment fund portfolios, or simply because liquidity shocks to international investors spread to different countries as they sell assets in their portfolio to restore liquidity—may work like a market test for EMs. ${ }^{3}$ As Calvo and Talvi (2005) point out, these market tests can be followed by a painful adjustment

\footnotetext{
${ }^{1}$ DLD is related but quite different from Original Sin, a concept popularized by Eichengreen, Hausmann and Panizza (2005), which encompasses foreign debt and, in some empirical tests, excludes the domestic capital market (see, e.g., Frankel and Cavallo (2004)).

${ }^{2}$ See Calvo, Izquierdo and Talvi (2003), Calvo, Izquierdo and Mejía (2004), Calvo and Talvi (2005), and Calvo, Izquierdo and Loo-Kung (2005).

${ }^{3}$ For a discussion of a rationale for the spread of liquidity shocks see, for example, Calvo (1999).
} 
and sharp reduction in economic growth, or become a minor recession depending on domestic vulnerabilities.

The present paper is, first and foremost, an attempt at extracting stylized facts characterizing $3 \mathrm{~S}$ output collapses, and, in particular their post-collapse recovery phase, i.e., how economies come out from output collapses that occur in the context of $3 \mathrm{~S}$. Periods of $3 \mathrm{~S}$ offer a unique natural experiment: the shock is large and easy to identify, it originates in global capital markets, and it hits several countries at the about the same time.

These episodes are characterized by two salient features. First, there is a dramatic collapse in output (for our sample of collapses, the average fall in GDP is 10 percent) accompanied by a collapse in credit, but without any correspondingly sharp collapse in either physical capital or the labor force. Second, recovery to pre-crisis output is swift and "credit-less"-i.e., output grows back to pre-crisis levels without any significant recovery in domestic or external credit. Thus, although a credit crunch appears to be central for explaining output collapse, recovery can take place without credit. This remarkable phenomenon that resembles the feat of the proverbial bird "rising from its ashes" prompted us to call it Phoenix Miracle.

To avoid misunderstandings, it is worth pointing out at the outset that although credit cannot account for the strong output expansion following output collapse, it would be wrong to infer that credit is irrelevant. Our conjecture, spelled out in the model of Section IV, is that, faced with a credit crunch, the economy strives to develop new sources of financing that lie outside the formal credit market. Developing these new sources, such as postponing investment projects to create liquidity, is costly. Actually, 
some of the costs could linger on long after the crisis episode is over, which is in line with the Cerra and Chaman Saxena (2005) finding that, on average, crises have a negative effect on long-run growth. ${ }^{4}$

We focus on a sample of EMs that are integrated in world capital markets — and, thus, are likely to be affected by $3 \mathrm{~S}$ events. ${ }^{5}$ The sample includes most of the recent high-profile crisis episodes, such as the Tequila crisis episodes (Argentina 1995, Mexico 1995, Turkey 1995), East Asian crisis episodes (Indonesia 1998, Malaysia 1998, Thailand 1998) and the Russian crisis episodes of the late 1990s (Ecuador 1999, Turkey 1999, Argentina 2002), as well as the Latin American Debt Crisis episodes of the 1980s (Argentina 1982, Brazil, 1983, Chile 1983, Mexico 1983, Peru 1983, Venezuela 1983, Uruguay 1984).

\section{Main Findings}

Output collapse episodes that occurred in the context of $3 \mathrm{~S}$ exhibit a clear-cut pattern summarized by the following characteristics: ${ }^{6}$

- Post-collapse recoveries tend to be steep, i.e., economic activity reaches its precrisis levels relatively quickly, on average, less than three years following the output trough.

- Total factor productivity (TFP)—computed according to standard growth accounting, using capital and labor as factors of production—mimics the behavior of output: It falls sharply during the collapse phase, only to recover swiftly

\footnotetext{
${ }^{4}$ In contrast to Cerra and Chaman Saxena (2005), however, who examine recoveries from recessions for a large set of developed and developing countries, we focus on $3 \mathrm{~S}$ collapses, comprising episodes in which the dominant shock is financial and output contraction is "large."

${ }^{5}$ The sample comprises countries tracked by JP Morgan in its global Emerging Market Bond Index. See Section II for more details.

${ }^{6}$ As will be described in Section II, we define and output collapse as a $4.4 \%$ decline of GDP from pre-crisis peak to trough (corresponding to the median contraction in our sample).
} 
afterwards. Moreover, variations in TFP account for the bulk of the variation in output throughout the collapse-recovery process. $^{7}$

- The capital stock remains relatively constant throughout the collapse-recovery phase, while investment collapses together with output, and recovers weakly by the time output recovers to pre-crisis levels.

- Domestic and external credit collapse together with output, but output recovery materializes with virtually no recovery in either domestic or external credit, i.e. the recovery could be labeled "credit-less."

A key piece of evidence that provides some clues about the nature of $3 \mathrm{~S}$ collapses and their recovery phase is the behavior of TFP, shown in Figure 1, panel (A). ${ }^{8} 9$ Figure 1 suggests that at the time output recovers, TFP is not significantly different from that prevailing before $3 \mathrm{~S}$ (this is confirmed by empirical tests in Section III). But TFP falls sharply together with output, and recovers fully by the time of output reaches its precrisis levels, displaying the same V-shaped pattern depicted by output. Moreover, TFP accounts for the bulk of the variation in output in both the collapse and recovery phase.

\footnotetext{
${ }^{7}$ Employment also follows a V-shaped pattern similar to that of output, but it only accounts for a small fraction of the variation in output relative to TFP.

${ }^{8}$ Each of the variables presented there is an average of the twenty-two $3 \mathrm{~S}$ collapse episodes that will be discussed in Section III along with formal tests.

${ }^{9}$ We define a pre-crisis peak as the time when output reaches its maximum value before a trough, and a full recovery as the time when output recovers to pre-crisis peak levels following collapse. See Section II for more details.
} 
Figure 1. The Phoenix Miracle: A Comparison with the US Great Depression

Emerging Markets

(A)

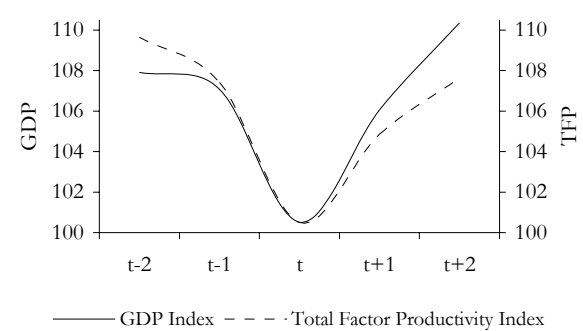

(B)

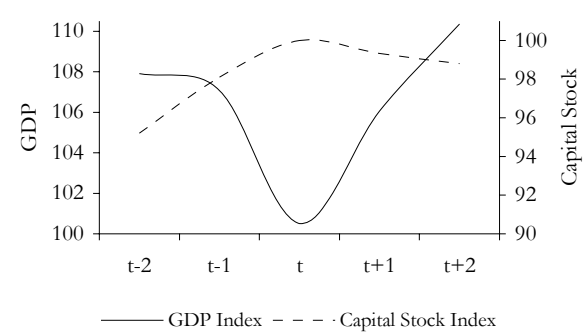

(C)

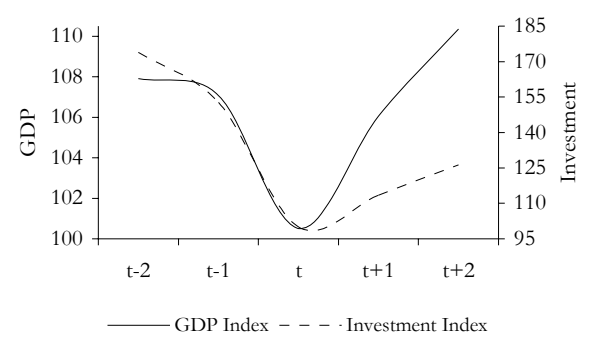

(D)

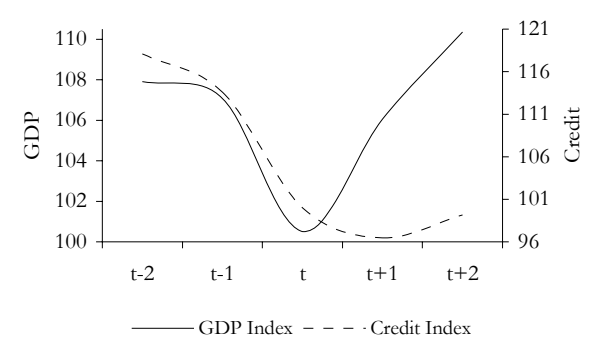

(E)

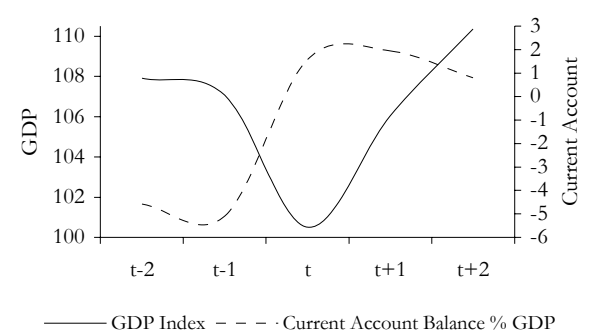

Note: Various Sources. See Data Appendix for details.
US Great Depression

(F)

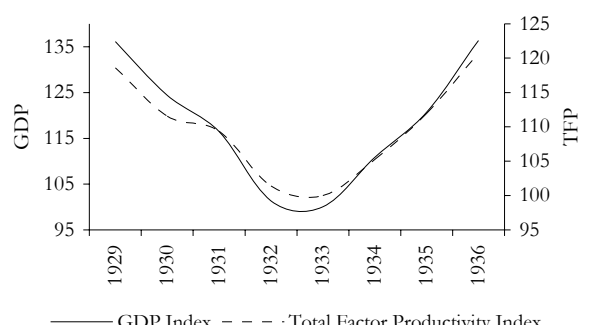

(G)

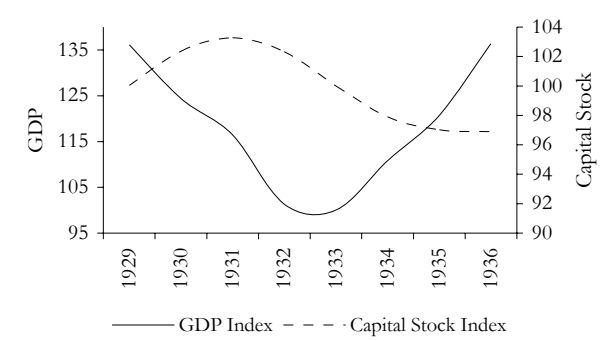

$(\mathrm{H})$

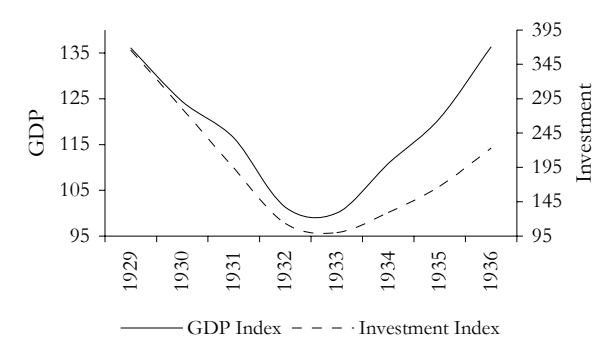

(I)

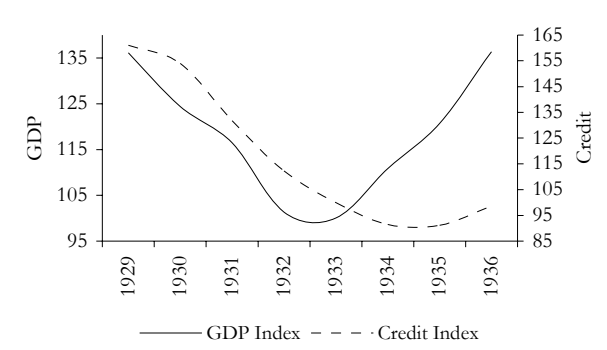

(J)

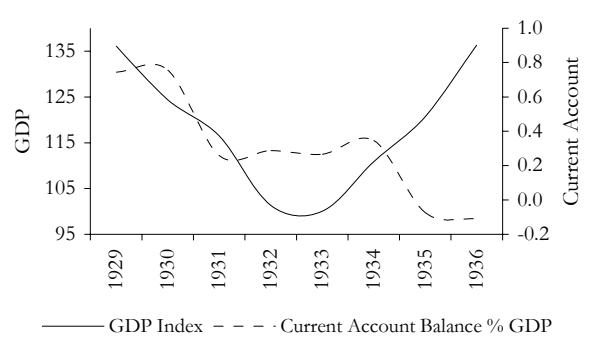


This severe fall and subsequent "resurrection" in TFP is very intriguing because, if attributed only to technological shocks, it would imply an implausibly large and sudden loss of memory, a "massive Alzheimer's attack," so to say, regarding the production process, and a subsequent and sudden recovery from Alzheimer's disease following output collapse. These swings in measured TFP are hard to attribute to technological factors. An alternative conjecture is that true TFP remains roughly the same throughout the collapse-recovery process, and that swings in measured TFP stem from a key missing variable — a main suspect being financial constraints associated with $3 \mathrm{~S}$.

Stagnation of true TFP is not an implausible outcome. During a phase of dramatic financial disarray, firms are likely to devote much of their attention to the recomposition of their financing, paying little attention to increasing factor productivity. Moreover, constancy in TFP throughout the collapse-recovery process would justify dating "recovery" by the point in time when output attains its pre-crisis level. ${ }^{10}$ This definition of full recovery leads us to conclude that output recovery is swift. But swift recovery is not tantamount to asserting that the financial crisis is costless. In fact, economies subject to these crises may take a long time to recover to trend levels that would have prevailed in the absence of a crisis. Thus, our finding of a swift recovery to pre-crisis levels is not inconsistent with evidence presented for other major crises, such as the US Great Depression, indicating that it takes a prolonged period of time for output to recover to trend levels (see, for example, Cole and Ohanian (1999)).

Panel (B) shows the relative constancy of the capital stock throughout the collapse-recovery process. Panel (C) illustrates that investment falls hand-in-hand with

\footnotetext{
${ }^{10}$ If our conjecture about the existence of a key missing variable proves to be right, TFP during a crisis episode could tongue-in-cheek be called "Totally Fictitious Productivity."
} 
output, and recovers feebly as output bounces back to pre-crisis levels. In fact, it is precisely the collapse in investment, and its failure to recover, that explains the constancy of the capital stock. Panels (D), and (E) contrast the V-shaped pattern in output from precrisis peak to full recovery with that of domestic bank credit to the private sector and external credit (proxied by the current account balance), which collapse together with output, but fail to recover as output goes back to pre-crisis levels. As noted above, this "credit-less" recovery is what we call "Phoenix Miracle".

Such a surprising set of characteristics of post-collapse recoveries in EMs led us to the question of whether one of the most studied—and still controversial—episodes of output collapse, i.e., the US 1930s Great Depression, could also be catalogued as a Phoenix Miracle. Besides, crises involving severe output losses are the order of the day in EMs, and comparisons with the US Great Depression are potentially illuminating both for understanding the forces at work in EM crises, and in providing a fresh look at the US Great Depression in light of EM experience.

Our findings show that the parallels are striking, but so are the differences, and both are quite revealing. The US Great Depression episode is similar to that of EMs in three dimensions: (i) Measured TFP and output initially collapse, and eventually recover to pre-crisis levels (Figure 1, panel (F)). (ii) The capital stock remains relatively constant, while investment collapses together with output but recovers only feebly as output reaches its pre-crisis levels (Figure 1, panels $(\mathrm{G})$ and $(\mathrm{H})$ ). (iii) Post-collapse recovery is “credit-less", i.e., it materializes with virtually no recovery in domestic bank credit (see Figure 1, panel (I)). 
However, the US Great Depression differs substantially from output collapses in EMs in many other aspects. To begin with, in the Great Depression the current account balance as a share of GDP slightly deteriorates throughout the collapse-recovery phase. This suggests that the credit crunch mostly stems from the domestic banking system rather than from the external front. Second, during the contraction phase, the US Great Depression exhibits price deflation, no currency devaluation, and a substantial increase in real wages (see Figure 2, Panels E through H). ${ }^{11}$ In stark contrast to these developments, the output collapse phase in EMs is characterized by acceleration in price inflation, sharp nominal (and real) currency depreciation, and sharp fall in real wages (see Figure 2, panels A through D).

These differences are quite illuminating for two reasons: First, by remaining on gold, the US kept its exchange rate unchanged at its pre-crisis peak level for almost four years. Several prominent explanations of the Great Depression assign a crucial role to the Gold Standard and the limits it imposed on expansionary monetary policy. Friedman and Schwartz (1963), for example, suggest that if money supply had not been allowed to fall (a policy that the Federal Reserve could have implemented), the Great Depression would at worst be listed among the set of mild (and boring) US recessions, as deflation would have been avoided. In contrast to the US deflationary experience, EM collapse episodes are characterized by a steady rise in the nominal exchange rate and an acceleration of inflation during the output contraction phase, a fact that calls into question the hypothesis that price deflation per se is an essential ingredient in triggering output collapse.

\footnotetext{
${ }^{11}$ Real wages are obtained using as deflator the wholesale price index.
} 
Figure 2. Selected Variables: A Comparison with the US Great Depression

Emerging Markets

(A)

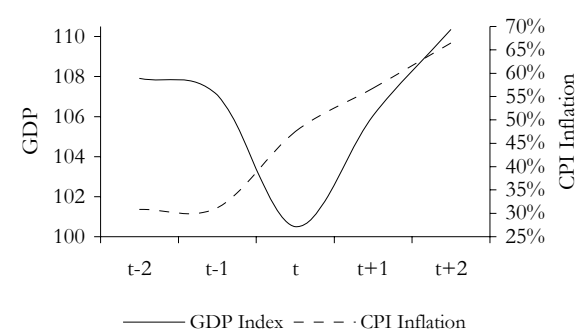

(B)

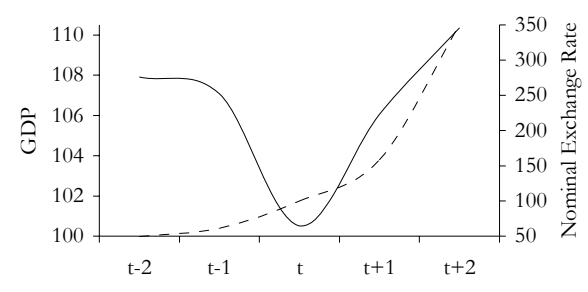

(C)

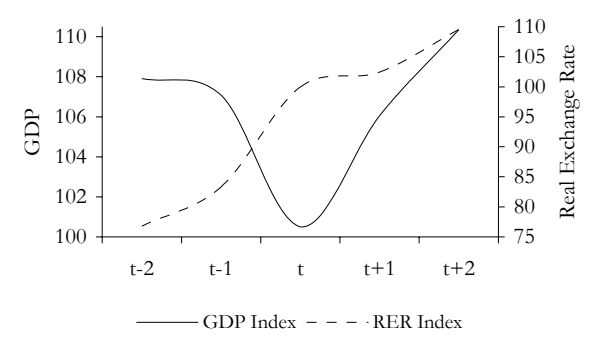

(D)

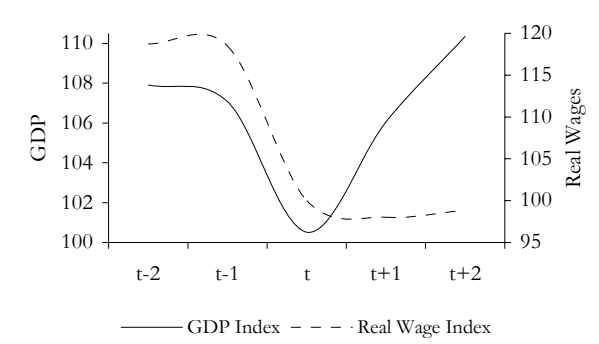

US Great Depression

(E)

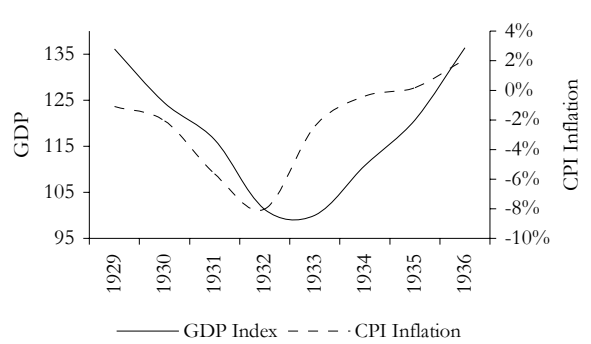

(F)

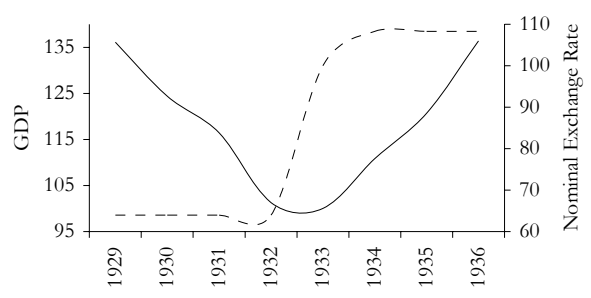

(G)

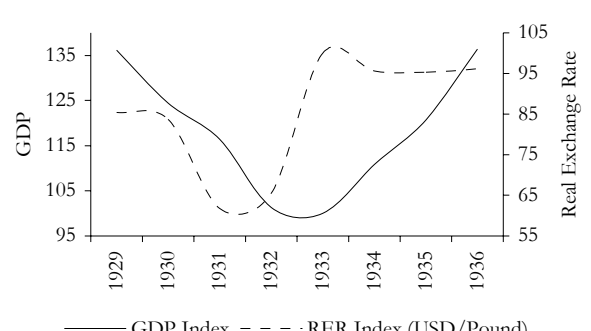

(H)

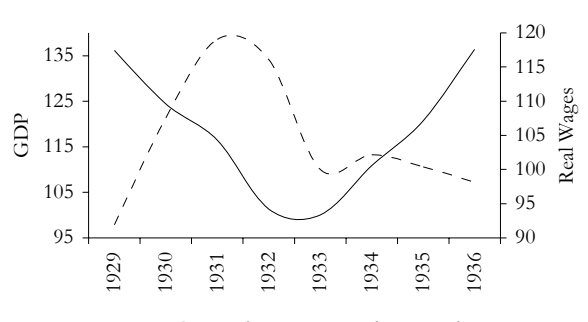

Note: Various Sources. See Data Appendix for details.

Second, leading explanations for the size and persistence of output contraction during the Great Depression have relied on two major rigidities, namely, nominal wage stickiness and non-contingent financial contracts, that, in the face of price deflation, caused significant increases in real output wages and in real debt- the latter known as 
Debt Deflation, discussed by Irving Fisher (1933). ${ }^{12}$ The real wage increase argument, due to nominal wage rigidities and price deflation, is clearly consistent with rising unemployment. On the other hand, the Debt Deflation argument relies on the existence of largely unanticipated and sizable price falls that result in a sharp increase in real expost interest rates, triggering bankruptcies in highly indebted sectors and possibly bringing about financial crisis. Interestingly, the evidence presented in this paper for the EM sample of output collapses strongly suggests that nominal wage stickiness is not a key factor since, as noted, the real wage sharply falls during the phase of output collapse (see Figure 1, Panel D). This evidence, thus, suggests that Debt Deflation, or some financial crisis variant, may be at the heart of all of these crises (including the Great Depression).

EM crises triggered during periods of $3 \mathrm{~S}$ have been characterized by a sharp increase in real interest rates faced by borrowers. ${ }^{13}$ However, Debt Deflation as such cannot be claimed to be a relevant factor in our EM sample because, as noted, currency devaluation and inflation acceleration rather than price deflation are the rule in EM crisis episodes. Nonetheless, a similar effect is produced by Liability Dollarization, i.e., foreign-exchange denominated debt, a common feature in EMs. ${ }^{14}$ Under those circumstances, real depreciation increases the output value of outstanding debt (particularly in non-tradable firms), causing the real value of debt to inflate. Thus, sharp nominal (and real) currency devaluation in the presence of Liability Dollarization may

\footnotetext{
${ }^{12}$ For a very useful exposition and evidence on these leading explanations of the US Great Depression, see Bernanke (1995).

${ }^{13}$ For example, in the aftermath of the Russian crisis in August 1998, country risk, as measured by aggregate indices such as J.P. Morgan's Emerging Market Bond Index, skyrocketed beyond 1700 basis points above US Treasuries.

${ }^{14}$ As noted in footnote 1 , in the literature there are different concepts associated with this phenomenon. By Liability Dollarization we refer to any situation in which foreign-exchange debts play a prominent role.
} 
have worked in EMs as a new version of Fisher's Debt Deflation syndrome, and may be central in explaining output collapses.

The rest of the paper is organized as follows: Section II discusses the choice of sample and elaborates further on the object of study. Section III highlights key stylized facts of post-collapse recoveries following $3 \mathrm{~S}$ episodes in EMs, and provides empirical support for the significance of these facts. It also highlights in detail similarities and differences between EM collapses and the US Great Depression. Section IV introduces a partial equilibrium model with financial frictions that helps to capture the essential elements of the observed Phoenix Miracle phenomena concerning output, investment and credit. Section V concludes with a brief summary and some implications.

\section{Output Collapse in Emerging Markets: The Sample}

Given the considerations outlined above regarding 3S episodes, natural candidates for the analysis of collapses in output related to systemic financial turmoil are countries that are integrated into the world capital market. One possible measure of integration is the ability to place a sizeable amount of international bonds. For this reason, the sample selected for the analysis is composed of countries that are tracked by JP Morgan to construct its global Emerging Market Bond Index, or global EMBI, with observations spanning the period $1980-2004 .^{15}$ This sample increases the chances of capturing episodes stemming from systemic credit shocks, as opposed to the myriad of other factors behind output contractions.

\footnotetext{
${ }^{15}$ The list of countries includes Argentina, Brazil, Bulgaria, Chile, Colombia, Croatia, Czech Republic, the Dominican Republic, Ecuador, El Salvador, Hungary, Indonesia, Ivory Coast, Lebanon, Malaysia, Mexico, Morocco, Nigeria, Panama, Peru, Philippines, Poland, Russia, South Africa, South Korea, Thailand, Tunisia, Turkey, Ukraine, Uruguay, and Venezuela (see Data Appendix for details).
} 
Unless swings in measured TFP were attributed to technological factors, periods of 3S involving output collapses and Phoenix Miracle-type recoveries are highly suggestive of sudden "underutilization of capacity" ${ }^{16}$ This is so, because after large drops in output, it would be difficult to rationalize speedy post-collapse recovery, unless idle resources are part of the equation (recall that capital and labor exhibit small fluctuations, and there is virtually no recovery in foreign or domestic credit). It is for this reason that we focus on large output downturns.

We focus next on the definition of output collapse. We start by looking at cumulative contractions in output-i.e., the accumulation of consecutive yearly contractions in output—for our sample of EMs throughout the period 1980-2004. We cover this particular timeframe because it represents a phase where international capital flows to EMs became substantial (after their sustained rise in the 1970s) and subject to considerable aggregate swings, as shown in Figure 4.

The resulting distribution of cumulative contractions comprising all countries and periods is shown in Figure 5, for a total of 83 episodes (see Table 1 of the Appendix for a complete list). It is clearly asymmetric, with an average cumulative contraction of 7.8 percent, and a large concentration around small drops in output. We use this distribution to define a collapse as a contraction that lies to the left of the median, implying a cut-off output contraction of 4.4 percent. For each of these episodes, we define a pre-crisis peak, trough and full recovery point. ${ }^{17}$ The pre-crisis peak is the period displaying the

\footnotetext{
${ }^{16}$ See the model in Section IV where "capacity underutilization" is defined as a deviation from financially unconstrained optima.

${ }^{17}$ To make sure that we are capturing the appropriate trough point for collapse episodes, we look for additional contractions in output to the right of the initially detected trough that do not qualify as collapses and lie no more than three periods away from the initially detected trough (thus allowing for temporary positive growth "blips" of up to two periods and a "double dip" contraction). If the cumulative collapse in
} 
maximum level of output preceding a trough, and the full recovery point is that period in which the pre-crisis peak output level is fully restored. ${ }^{18}$ A trough is the local minimum following the onset of a crisis. This methodology led to the identification of 45 episodes of output collapse spanning the period 1980-2004.

\section{Figure 4. Real Private Capital Flows to Emerging Markets}

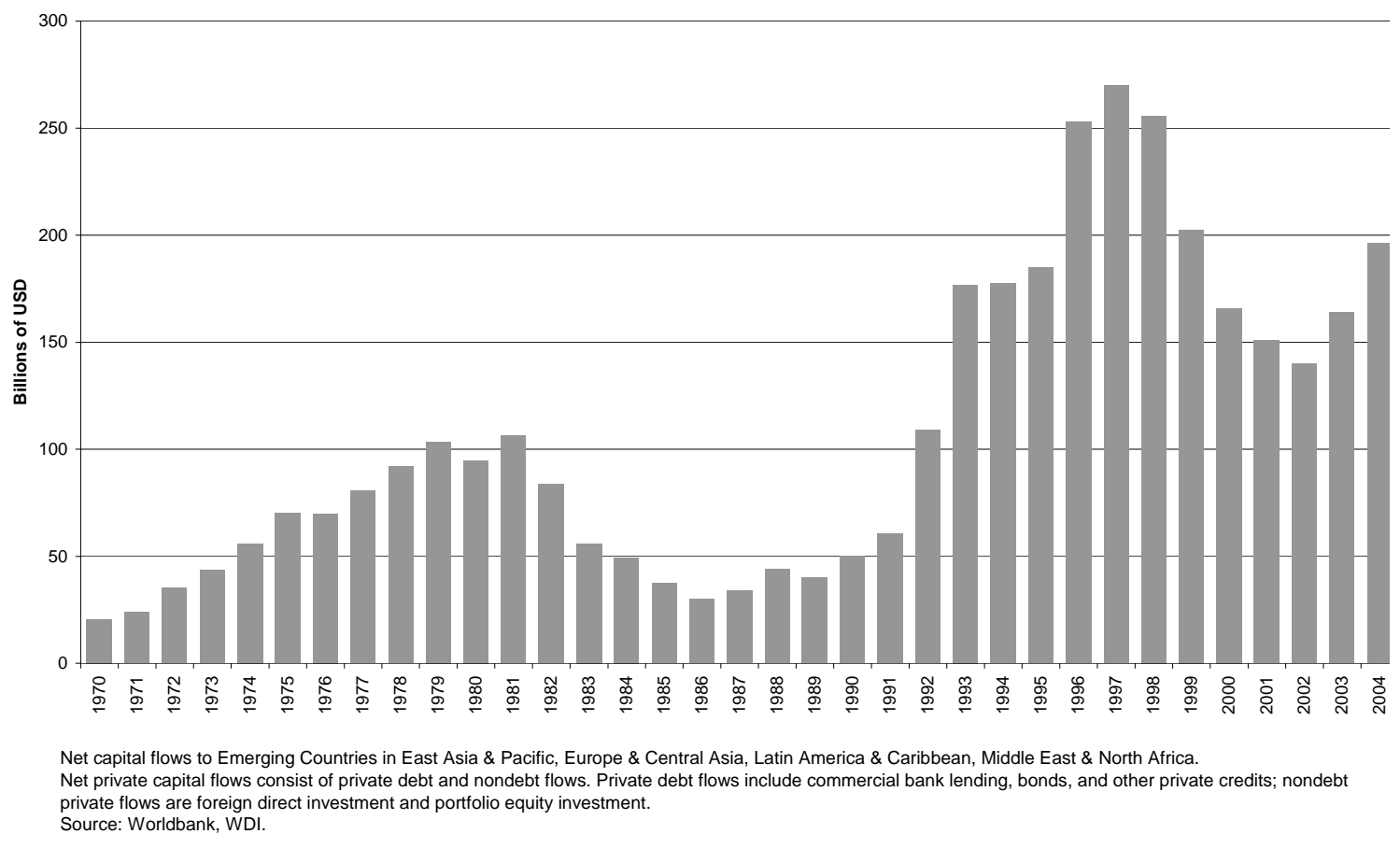

output at the new trough exceeds that of the initially detected trough, we extend the collapse episode to include the new trough point, so that it becomes part of the same episode. This procedure led to the reclassification of trough points for only five episodes out of a sample comprising 83 episodes, namely, Brazil 1983, Nigeria 1984, Peru 1990, Czech Republic 1992, and Croatia 1993.

${ }^{18}$ For the very few collapse episodes in which output did not fully recover before being hit by another collapse episode, we take the observation showing the highest value of output prior to the next collapse as the full recovery point. This occurred for only a few episodes: Argentina 1982, Brazil 1990, Côte d'Ivoire 1990 and 2000, Russia 1996, and Bulgaria 1993. 
Figure 5. Distribution of Cumulative Contractions in Output

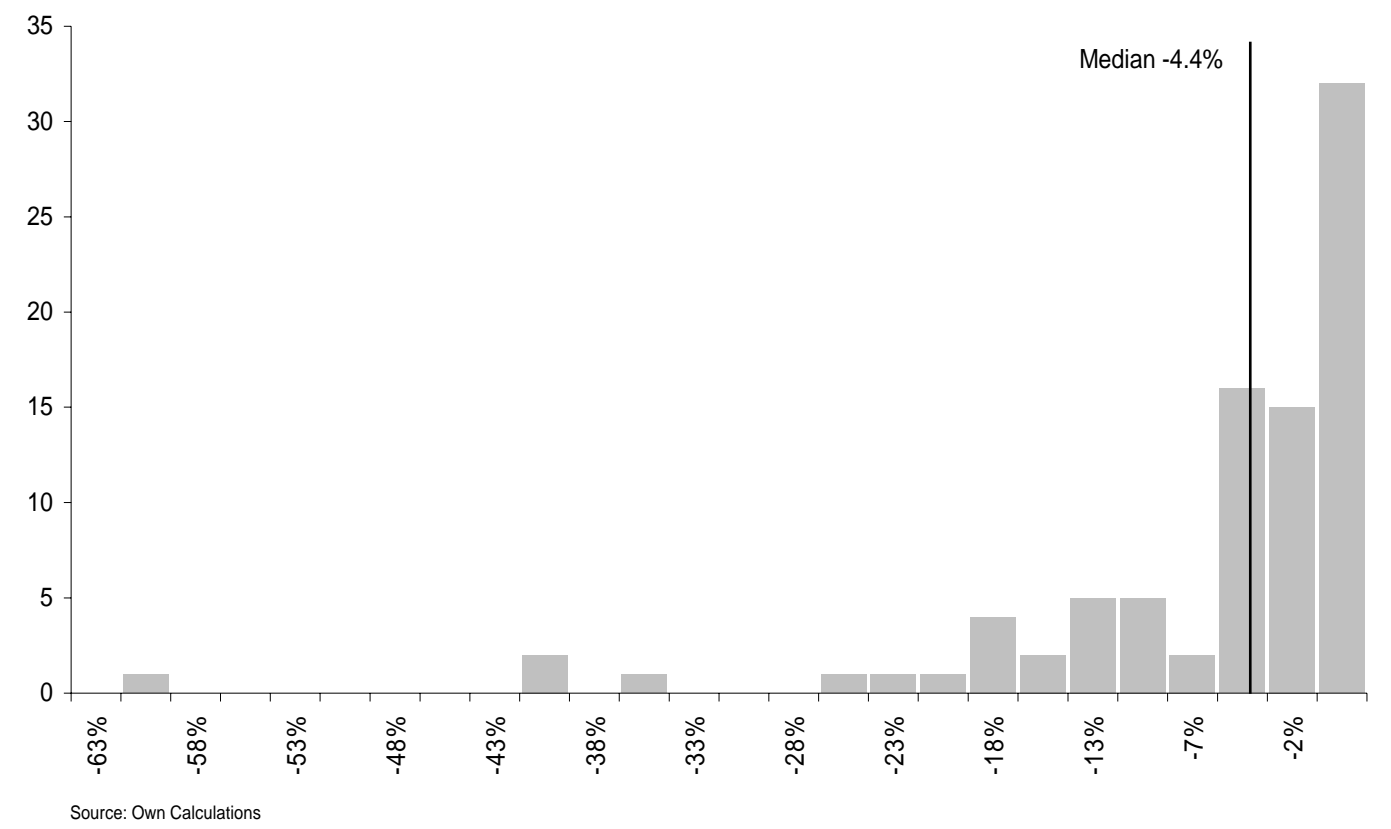

With these episodes at hand, we now turn our attention to those that occurred during periods of $3 \mathrm{~S}$. We believe this is a key element to consider, not only because of the reasons already stated earlier, but also because, in contrast to non-3S episodes that may cover a wide variety of shocks with several possible outcomes, $3 \mathrm{~S}$ episodes are characterized by very specific phenomena related to disruption in access to international credit markets.

\footnotetext{
${ }^{19}$ To make sure that we are capturing the appropriate trough point for collapse episodes, we look for additional contractions in output to the right of the initially detected trough that do not qualify as collapses and lie no more than three periods away from the initially detected trough (thus allowing for temporary positive growth "blips" of up to two periods and a "double dip" contraction). If the cumulative collapse in output at the new trough exceeds that of the initially detected trough, we extend the collapse episode to include the new trough point, so that it becomes part of the same episode. This procedure led to the reclassification of trough points for only five episodes out of a sample comprising 83 episodes, namely, Brazil 1983, Nigeria 1984, Peru 1990, Czech Republic 1992, and Croatia 1993.

${ }^{20}$ For the very few collapse episodes in which output did not fully recover before being hit by another collapse episode, we take the observation showing the highest value of output prior to the next collapse as the full recovery point. This occurred for only a few episodes: Argentina 1982, Brazil 1990, Côte d'Ivoire 1990 and 2000, Russia 1996, and Bulgaria 1993.
} 
3S collapses are portrayed as output collapses that occur during a period of plummeting capital flows in a context of substantial turmoil in global capital markets. In similar fashion to Calvo, Izquierdo and Loo-Kung (2005), we define a 3S window as the union of

- a capital-flow window containing a large fall in capital flows for a given country exceeding two standard deviations from its mean (that starts when the fall in capital flows exceeds one standard deviation, and ends when it is smaller than one standard deviation) that overlaps at any point in time with

- an aggregate-spread window containing a spike in the aggregate EMBI spread exceeding two standard deviations from its mean (which starts when the aggregate EMBI spread exceeds one standard deviation, and ends when it is smaller than one standard deviation). ${ }^{21}$

If either the pre-crisis peak or trough of a previously identified output collapse episode falls within the $3 \mathrm{~S}$ window, it is classified as a $3 \mathrm{~S}$ collapse. This classification yields a group of twenty-two $3 \mathrm{~S}$ collapses that contains most of the well-known crises throughout the 1980s and 1990s, including the Latin American Debt Crisis episodes (Argentina 1982, Brazil 1983, Chile 1983, Mexico 1983, Peru 1983, Venezuela 1983, Uruguay 1984), the Tequila crisis episodes (Argentina 1995, Mexico 1995, Turkey 1995), the East Asian crisis episodes (Indonesia 1998, Malaysia 1998, Thailand 1998) and the Russian crisis episodes of the late 1990s (Ecuador 1999, Turkey 1999, Argentina 2002). Table 2 of the Appendix provides a complete list.

\footnotetext{
${ }^{21}$ Given that the EMBI is not available for the 1980s, we used the Federal Funds rate instead as a proxy that captures the cost of access to international financing for EMs. This is a reasonable assumption since bank credit was the dominant source of funding for EMs during that period (see Data Appendix for details).
} 


\section{Output Collapses in EMs under Systemic Capital Market Turmoil: Stylized}

\section{Facts}

We now turn to the analysis of the behavior of a key set of variables throughout 3S collapse episodes. We first take a look at the performance of five variables, namely, TFP, the capital stock, investment, private sector bank credit, and the current account balance (as a measure of external financing) relative to GDP. Behavior for the average episode is shown in Figure 1, covering a five-year window centered on troughs in output that tracks the whole phase from pre-crisis peak to full recovery. Notice that given the nature of the analysis at hand, we focus on "full recovery" in output levels as opposed to trends. The fact that true TFP likely remains constant throughout the collapse-recovery process (as it was argued in the introduction, and will be shown below), justifies dating "recovery" by the point in time when output attains its pre-crisis level. Otherwise, if true TFP had risen in the interim, full recovery would have to take that into account by, for example, dating recovery by the point in time when the output/true TFP ratio goes back to its pre-crisis level. ${ }^{22}$

The first feature that can readily be observed is that the average path of GDP from pre-crisis peak to full recovery is clearly V-shaped. Average output collapses by 7 percent within a two-year period, and recovers fully in just about two years. ${ }^{23}$ Average measured TFP follows a very similar pattern: it falls by 8.4 percent from peak to trough and then quickly recovers, filling almost 78 percent of the initial gap at the time output

\footnotetext{
${ }^{22}$ Besides, working with trend levels would immediately pose one concern: Many EM crisis episodes are too recent to obtain proper estimates of trend levels.

${ }^{23}$ The figure of 7 percent, indicating the fall in average output differs from the average fall in output across all 22 episodes, which is 10 percent. Similarly, the recovery phase of average output is 2 years, while the average recovery phase across all 22 episodes is 2.8 years.
} 
recovers fully (see Figure 1 panel A). ${ }^{24}$ It is important to highlight that about 100 percent of the fall in average output from peak to trough can be accounted for by the fall in measured TFP. ${ }^{25}$ Similarly, 76 percent of the increase in output from trough to recovery is explained by increases in measured TFP. This is a key stylized fact that puts into question the explanation that output recovery may be due to technological change. It rather suggests that TFP, as measured, is missing a central element, e.g., the effects of credit disarray on "capacity utilization".

The average capital stock increases by 5 percent from peak to trough, falls slightly (1.2 percent) from trough to recovery (Figure 1, Panel (B)), and is only 3.8 percent higher than its pre-crisis level by the time of full recovery in output. This behavior is consistent with the dramatic fall in investment, which exceeds that in output. Figure 1, Panel C shows that average investment hits its trough at the same time that GDP does, declining by about 42 percent in real terms relative to its value at pre-crisis peak time. At the time of full recovery, two years after the slump, only 35 percent of the investment gap has been filled.

In terms of domestic financing, Panel D of Figure 1 shows that average domestic bank credit to the private sector collapses by about 15 percent in real terms from precrisis peak to trough, and none of the initial credit gap is closed at the time of full

\footnotetext{
${ }^{24}$ For each episode in the sample, measured TFP is obtained as the residual of a Cobb-Douglas production function with physical capital and labor as arguments, of the type $Y_{t}=A_{t} K_{t}{ }^{\alpha} L_{t}{ }^{(1-\alpha)}$ (where Y is output, A is measured TFP, $\mathrm{K}$ is the capital stock, and $\mathrm{L}$ is employment). Capital stocks and investment data as of 1980 are obtained from Nehru and Dhareshwar (1993). The capital stock is updated by using investment data at constant prices from our dataset, assuming a depreciation rate of 8 percent per year (see Mendoza and Durdu (forthcoming) for an estimation of the depreciation rate for the Mexican case, which we take as representative of our sample of EMs). A uniform share of capital in total income ( $\alpha)$ of 0.4 is given to all countries in the sample (following Nehru and Dhareshwar (1993)).

${ }^{25}$ When estimating the contribution of each factor to changes in $(\log )$ output, we make use of the fact that for the Cobb-Douglas production function outlined above, $(\log )$ changes in output are determined by: $\log Y_{t}-\log Y_{t-i}=\log A_{t}-\log A_{t-i}+\alpha\left(\log K_{t}-\log K_{t-i}\right)+(1-\alpha)\left(\log L_{t}-\log L_{t-i}\right)$
} 
recovery. External financing, as measured by the current account balance, follows a pattern similar to that of domestic financing (see Figure 1, Panel E). The average current account balance adjusts by about 6 percentage points of GDP from pre-crisis peak to trough, and it remains relatively constant at high surplus levels thereafter, implying that only close to 13 percent of the initial current account reversal is closed at the time of full recovery.

We complement this visual inspection with statistical tests, starting with the behavior of TFP. We are interested in determining significant percentage differences in TFP between pre-crisis peak, trough, and full recovery points, based on individual episode values. In analogous fashion to difference-in-means tests, we run a regression of percentage differences in TFP (covering all episodes) against a constant to determine their significance using standard t-statistics. This procedure is applied to differences from pre-crisis peak to trough, trough to full recovery, and pre-crisis peak to full recovery. Results are shown in Table 1. They indicate that indeed measured TFP falls on average by about 9.5 percent from pre-crisis peak to trough (significant at the 1 percent level), a very similar figure to that of the average collapse in GDP from pre-crisis peak to trough of 10 percent. Measured TFP quickly catches up, increasing from trough to full-recovery time by 10 percent (significant at the 1 percent level). As a matter of fact, measured TFP at full recovery time is not significantly different prevailing TFP levels at pre-crisis peak time.

We also report the behavior of the capital stock, which increases on average by 3.7 percent from peak to trough (significant at the 1 percent level), and falls at a rate of 3.2 percent from trough to recovery (significant at the 10 percent level) - resulting in no 
significant change from peak to recovery. Investment as a share of GDP collapses on average by about 34 percent from pre-crisis peak to trough. The investment-to-GDP ratio remains around 23 percent below its pre-crisis peak value at full recovery time (all these differences are significant at the 1 percent level).

Table 1. 3S Collapse Episodes: Average Differences Along Pre-Crisis Peaks, Troughs, and Full Recovery Points

\begin{tabular}{|lccc|}
\hline & Peak to Through & Trough to Recovery & Peak To Recovery \\
Total Factor Productivity & $-9.497 * * *$ & $9.874 * * *$ & -0.785 \\
& {$[1.474]$} & {$[1.719]$} & {$[1.378]$} \\
Capital Stock & 17 & 17 & 17 \\
& $3.735^{* * *}$ & $-3.177^{*}$ & 0.639 \\
& {$[1.124]$} & {$[1.669]$} & {$[2.489]$} \\
Investment/GDP & 21 & 21 & 21 \\
& $-34.234^{* * *}$ & $20.210^{* * *}$ & $-23.240^{* * *}$ \\
Credit/GDP & {$[4.202]$} & {$[6.551]$} & {$[5.030]$} \\
& 22 & 22 & 22 \\
Current Account Balance/GDP & 3.948 & $-20.014 * * *$ & $-16.768^{* *}$ \\
& {$[5.455]$} & {$[5.542]$} & {$[7.020]$} \\
& 22 & 22 & 22 \\
& $5.706^{* * *}$ & -1.545 & $4.161^{* * *}$ \\
\hline Note: Standard errors in brackets. Number of episodes is also reported. Coefficients show percentages \\
differences for Total Factor Productivity, Capital Stock, Investment and Credit, and differences in percent \\
of GDP for the Current Account Balance. \\
* significant at 10\%; ** significant at 5\%; ** significant at 1\% & & {$[1.359]$} \\
\hline
\end{tabular}

Tests on private sector credit as a share of GDP and the current account balance (a measure of foreign financing) as a share of GDP confirm the statistical significance of the behavior suggested by Panels D and E of Figure 1. Credit as a share of GDP does not change much from pre-crisis peak to trough (the estimated coefficient is small and not significantly different from zero), implying that the collapse in output is accompanied by a collapse in credit of similar magnitude. However, there is a large and significant drop of about 20 percent in the credit-to-GDP ratio between trough and full recovery, 
providing clear indication that credit remains stagnant at trough levels while GDP recovers (see Table 1). At full recovery, credit as a share of GDP is close to 17 percent lower than its prevailing value at the pre-crisis peak of the average episode ${ }^{26}$ An interesting difference with mild recessions is that "credit-less" recovery seems to be typical for output collapses, but not for mild recessions, in which credit falls together with output from peak to trough, but then recovers together with output. ${ }^{27}$ As a matter of fact, for mild recessions credit as a share of GDP at the time of full recovery is not significantly different from its pre-crisis value (see Appendix I for details). Thus, mild recessions are not Phoenix Miracles.

Similar results are obtained with foreign financing, where, after the crisis, a marked de-leveraging process takes place. This is shown by the severe adjustment in the current account balance, which increases significantly from pre-crisis peak to trough by about 6 percentage points of GDP (see Table 1) and remains in surplus thereafter (the difference from trough to full recovery is relatively small and not significant), implying that there should be large and significant changes between pre-crisis peak and full recovery; this is confirmed by the pre-crisis peak to full recovery test presented in Table 1. As a matter of fact, the current account balance remains on average about 4 points of GDP higher at full recovery than at pre-crisis peak (see Table 1).

In summary, episodes of output collapse in the context of $3 \mathrm{~S}$ seem to be characterized by substantial collapses in bank credit and the current account deficit, and

\footnotetext{
${ }^{26}$ An interesting observation is that more than two-thirds of the 22 episodes of systemic output collapse identified here were accompanied by "locally systemic" banking crises-i.e., failure of a large number of banks in the domestic banking system ("locally systemic" banking crisis episodes are obtained from Caprio and Klingebiel (2003)). This may help to explain why credit remains stagnant during the output recovery phase.

${ }^{27}$ Mild recessions are defined as cumulative contractions smaller than the median.
} 
little or no recovery in either at full recovery time, as if output were "rising from its ashes." Moreover, on average, there is no indication of a substantial change in either capital or employment levels, while there is a pronounced downswing and upswing in measured productivity, and a clear drop in investment as a share of GDP that fails to recover fully. ${ }^{28}$

One possible interpretation for the behavior of investment is that, in the absence of domestic or external credit, lower investment makes room for working capital accumulation which, coupled with "excess capacity", leads to output recovery. ${ }^{29} 30$ However, even if the drop in investment from pre-crisis levels were indeed used as a "source of financing" in times of loss of access to credit markets, there are other possible instruments of financial engineering that could compete with investment, as would be the case of greater tax evasion, temporarily lower wages, and the re-composition of earnings. An analysis of the financial engineering firms go through in times of $3 \mathrm{~S}$ is left for a future paper.

Having identified Phoenix Miracle-type behavior across 3S episodes, we now turn to the analysis of an additional set of variables of interest and explore their performance along the post-collapse recovery phase. This set of variables was chosen not only because they are interesting in their own right, but also in order to understand similarities and differences with one of the most studied output collapse episodes: the US Great Depression of the 1930s. This comparison is carried out along two dimensions. First, it

\footnotetext{
${ }^{28}$ Average employment levels fall slightly from peak to trough, and then slightly surpass pre-crisis levels at the time of output recovery. However, similar tests as those performed on other variables do not indicate a significant difference between pre-crisis peak and full-recovery levels.

${ }^{29}$ Some of these ingredients will be fleshed out formally in the model presented in Section IV.

${ }^{30}$ However, an alternative explanation would be that, following 3S, desired investment levels may be lower. For example, to the extent that $3 \mathrm{~S}$ is interpreted as evidence of an increase in uncertainty, it may be optimal to select lower investment levels.
} 
dwells on similarities in the post-collapse recovery phase. Second, it looks at differences during the collapse phase, in order to shed some light on the causes of output collapse.

Interestingly, the Great Depression also experienced a Phoenix Miracle-type process in that output recovery occurred with virtually no recovery of private sector credit. Measured TFP also displays the same pattern as that observed in our EM sample of $3 \mathrm{~S}$ output collapses: It falls by 15.7 percent from pre-crisis peak to trough, and it recovers completely at the time of full-recovery in output (see Figure 1, Panel $(\mathrm{F}))^{31}$ However, although measured TFP explains the largest proportion of the fluctuations in output from peak to trough and from trough to full recovery (55.3 percent and 60.8 percent, respectively), changes in employment are also responsible for a large share of output variation. ${ }^{32}$

The capital stock is very similar from pre-crisis peak to full-recovery (it falls by 3.1 percent), and again, this is linked to the large drop in investment (see Figure 1, Panels $(\mathrm{G})$ and $(\mathrm{H}))$. After having fallen by 73 percent from pre-crisis peak to trough, investment only closes 46 percent of the initial gap at the time of full recovery in output.

Credit to the private sector falls by 43 percent from pre-crisis peak to trough. At full recovery, it is still 39 percent less than the prevailing level at pre-crisis peak time, implying that only 11 percent of the initial credit gap was closed at the time of full recovery (see Figure 1, panel (I)). Output recovery was also "credit-less," and, thus, the US Great Depression is a Phoenix Miracle.

\footnotetext{
${ }^{31}$ Data on capital stock and employment levels used to derive TFP are obtained from Kendrick (1961). Just like for EMs, a Cobb-Douglas production function is used, but the share of capital in total income employed for calculations is 0.25 (also following Kendrick (1961)).

32 Variation in employment levels explains 44.7 percent of output variation from peak to trough, and 41.7 percent from trough to full recovery.
} 
However, differences become particularly evident when analyzing additional elements of the collapse phase. Figure 2 displays the behavior of domestic price inflation, the nominal and real exchange rate (RER), and real wages. Tests showing differences along pre-crisis peak, trough and full recovery points are presented in Table 2. Both sets of information support the following differences in the behavioral pattern for each of these variables:

- First and foremost, a key distinction that emerges on the monetary front is that, for EMs, annual inflation at the time of the trough is 16 percentage points above its pre-crisis peak levels (significant at the 1 percent level; see Table 2).

Moreover, the average cumulative increase in domestic prices from peak to trough is 93 percent. These developments contrast dramatically with the US Great Depression, where annual inflation at the time of the trough was -2.4 percent, compared to -1.1 percent at pre-crisis peak-in spite of the fact that devaluation took place precisely at the time of the trough, if anything, putting upward pressure on domestic prices. ${ }^{33}$ Moreover, cumulative deflation exceeded 17 percent from pre-crisis peak to trough.

- While in the US the nominal exchange rate (against gold) basically remained at its 1929 pre-crisis peak gold parity until mid-1933 (its trough year), EMs showed steady depreciation of the nominal exchange rate. However, the US devalued heavily around the time of the trough, so when considering pre-crisis peak to trough differences in the nominal exchange rate, the US experience (Figure 2, Panel F) is not very different from the behavior of the average EM (Figure 2,

\footnotetext{
${ }^{33}$ The available measure of the US consumer price index excludes food items.
} 
Panel B). Yet, differences become substantial at the time of full recovery, when average nominal exchange rates keep on rising dramatically in EMs, but not in the US.

- The dynamics for the RER also exhibited substantial differences. For EM episodes, the RER shoots up by about 49 percent from pre-crisis peak to trough (and this increase is significant at the 1 percent level, see Table 2). ${ }^{34}$ This fact is one of the key points regarding Sudden Stops and systemic crises made by Calvo, Izquierdo and Talvi (2003), stressing the impact of a sudden collapse in external financing of the current account deficit over the RER. More importantly, the RER does not go back to pre-crisis levels at full recovery. As a matter of fact, the RER is on average about 55 percent higher at full recovery than at the pre-crisis peak point (and significant at the 1 percent level, see Table 2). In contrast, the US experience is characterized by a steady real appreciation (vis-à-vis the pound) of about 23 percent until mid-1933 (covering most of the output contraction phase), and real depreciation of only 13 percent relative to pre-crisis peak levels by the time of full recovery.

- Another key difference emerges in the labor market. Real wages in the US (using wholesale prices as a deflator) hit a peak by 1931, marking an increase of 30 percent from pre-crisis peak levels. Even when output reaches its trough, real wages remain 9 percent higher than at their pre-crisis peak value. This is also the case at full recovery, when they are still 7 percent higher than at their pre-crisis peak. This is one of the main elements behind traditional explanations of the Great Depression: rising real wages in a context of domestic price deflation and

\footnotetext{
${ }^{34}$ An increase the RER is equivalent to a real depreciation of the domestic currency.
} 
limited nominal wage flexibility. By contrast, in EM crisis episodes the average fall in real wages from pre-crisis peak to trough is close to 10 percent (although this estimate is not significant at the 10 percent level). ${ }^{35}$ The fall continues from trough to full recovery by another 7 percent (but, again, it is not significant at the 10 percent level). When compounding these two differences into one, i.e., when analyzing behavior between pre-crisis peak and full recovery, the fall in real wages amounts on average to 20 percent, and it is significant at the 1 percent level (see Table 2). These facts show that even though there may be differences across countries in terms of the timing of the real wage adjustment process, there is definitely a substantial and significant drop in real wages by the time of full recovery, providing little support for the hypothesis that higher real wages are a dominant force behind output collapse in EMs.

Table 2. Phoenix Miracles: Average Differences along Pre-Crisis Peaks, Troughs, and Full Recovery Points for Selected Variables

\footnotetext{
${ }^{35}$ It is significant at the 16 percent level.

${ }^{36}$ Due to lack of data, coverage of real wages reduces the sample to 18 out of 22 episodes.
} 


\section{A Partial Equilibrium Model}

A plausible conjecture that emerges from these stylized facts is that deep output collapse and miraculous-looking recovery are the result of shocks and vulnerabilities in the international and domestic capital markets. This section will discuss a bare-bones model displaying those features. This is a useful exercise because it helps lifting the veil of mystery from these facts, and suggests modeling strategies for future research. To keep the analysis within reasonable bounds, we will conduct our discussion in terms of a partial equilibrium model. The model places major emphasis on frictions in the financial sector and analyzes the implications of a sudden increase in short-term interest rates on firms' decisions to produce, invest and borrow. ${ }^{37}$

We will focus on bank credit for working capital and, for the sake of simplicity, assume that firms have to finance physical capital with retained earnings. This pattern is especially relevant for economies in which there is poor effective creditor protection (as in Latin America, see IPES (2005)). Under those circumstances, credit will likely be constrained to small and short-term projects, like those associated with working capital, i.e., capital utilized to finance inventory accumulation or the wage bill. ${ }^{38}$

Consider the case in which output of domestic goods is produced by physical capital, $K$, and inventories, $Z$. Both have to be invested one period in advance. Capital lasts forever while inventories are fully consumed by the one-period production process. For the sake of simplicity, we will conduct the discussion under the assumption that capital has a perfect secondary market subject to no adjustment costs. Hence, assuming

\footnotetext{
${ }^{37}$ Actually, Neumeyer and Perri (2005) carry out a calibration exercise in a related RBC model. However, they do not address the issues raised here. Moreover, they abstract from the EM credit market imperfections that motivate the present analysis.

${ }^{38}$ The role of short-term credit as a disciplining device is a familiar theme in the microeconomic theory of finance. See, for example, Hart (1995).
} 
that the relative price of capital in terms of domestic output is unity, the firm can sell its capital for domestic output at a price equal to 1 . Let $A$ denote the firm's initial positive net assets (in terms of output), or net worth, which can be allocated to the accumulation of $K, Z$, and bank deposits, $D$. Then, assuming without loss of generality that the relative price of inventories with respect to capital is unity, we have

$$
A+B=K+Z+D
$$

where $B$ denotes one-period bank loans, respectively. $B$ can be utilized only to acquire inventories, and is constrained to be non-negative (i.e., firms can borrow from, but cannot lend to, banks). Thus,

$$
0 \leq B \leq Z
$$

The rate of interest at which firms borrow from banks (denoted by $r$ ) could be thought of as banks' active interest rate, as opposed to their passive rate (denoted by $\rho$ ) that applies to bank deposits. Moreover, $r>\rho$, and, to simplify the exposition, we will assume that the passive rate is small enough so that, under the conditions discussed in the rest of this section, firms will not have incentives to hold bank deposits. ${ }^{39}$

We will first focus on a one-period maximization problem in which the firm is supposed to maximize next-period initial net assets. Let us define the firm's gross revenue (denoted by $\pi$ ) by

$$
\pi=F(K, Z)-B(1+r)
$$

where gross production function $F$ is assumed to be linear homogenous. Besides, to ensure interior solutions in $K$ and $Z$, we assume that the flow production function satisfies

\footnotetext{
${ }^{39}$ In the spirit of partial equilibrium analysis, we will not model the spread between the active and the passive rates.
} 
Inada's conditions, for example. ${ }^{40}$ Denoting by $A$ ' the firm's next-period net assets, then, constraining the firm to hold no bank deposits (i.e., setting $D=0$ ), it follows that $A^{\prime}=\pi$. Thus, if bank deposits were not an attractive investment option for the firm, maximization of next-period initial net assets, $A^{\prime}$, would be equivalent to maximizing $\pi$, subject to the corresponding inequality constraints. We will follow that route, and later show that deposit rate $\rho$ can always be assumed small enough so that firms will find it optimal not to hold bank deposits. Thus, maximizing $\pi$ would be tantamount to maximizing next-period initial net assets (without imposing the constraint $D=0$ ).

We will now discuss the maximization of gross revenue $\pi$ in a more formal way. The problem consists of maximizing expression (3) with respect to $B$ and $Z$, subject to $D$ $=0$, and expressions (1) and (2). Hence, employing (1) to substitute for $K$, the associated Kuhn-Tucker expression is ${ }^{41}$

$$
F(A+B-Z, Z)-B(1+r)+\gamma(Z-B)+\xi B,
$$

where $\gamma$ and $\xi$ are non-negative parameters, and

$$
\gamma(Z-B)=\xi B=0 .
$$

Thus, the first-order conditions with respect to $B$ and $Z$ are, respectively,

$$
F_{K}(K, Z)-(1+r)-\gamma+\xi=0
$$

and,

$$
-F_{K}(K, Z)+F_{Z}(K, Z)+\gamma=0,
$$

where $F_{j}, j=K, Z$, denotes the partial derivative of function $F$ with respect to $j$.

\footnotetext{
${ }^{40}$ Let the flow production function be $f(K, Z)$; then, by definition, $F(K, Z)=f(K, Z)+K$.

${ }^{41}$ Notice that since constraints are linear, Kuhn-Tucker's regularity condition holds a fortiori.
} 
The Borderline Case. Let us first consider the case in which no constraint in expression

(2) is binding. Hence, by (5), (6) and (7), we have $\gamma=\xi=0$, implying that

$$
F_{K}(K, Z)=1+r \text {, }
$$

and

$$
F_{Z}(K, Z)=1+r .
$$

Hence, given that $F$ is linear homogeneous in $K$ and $Z$, we have

$$
\pi=F_{K} K+F_{Z} Z-B(1+r)=(1+r) A,
$$

where the first equality follows from linear homogeneity, and the second from equations (1), (8) and (9). Notice that in this case gross revenue is equivalent to lending $A$ at rate $r$ $>$ deposit rate $\rho$; thus, the asset-maximizing firm will set $D=0$, even if the constraint had not being imposed, showing that asset maximization is equivalent to gross revenue maximization. ${ }^{42}$ More interesting is the fact that gross revenue is independent of whether inventories are completely, partially or not at all financed with bank loans (i.e., gross revenue is independent on $B$ as long as it satisfies expression (2)). For the sake of concreteness, we will assume that under these circumstances, the firm chooses to entirely finance its inventories through bank loans-but the above indifference property will be revisited when we discuss the Deep Crisis case later on.

Notice that, given that $F$ is linear homogeneous, there exists a unique $r$ simultaneously satisfying equations (8) and (9). This is the reason why we refer to the present case as the Borderline Case. The two other "robust" cases are: the Normal case in which the gross marginal productivity of capital exceeds $1+r$, and the Deep Crisis

\footnotetext{
${ }^{42}$ This implication is unrealistic because firms are typically large holders of bank deposits. However, as a general rule, bank deposits are likely to be held for liquidity reasons, not because they are attractive investment projects. Thus, abstracting from the liquidity motive for the holding of deposits can be justified as a first approximation in a non-monetary model.
} 
case in which the gross marginal productivity of capital falls short of $1+r$. For future reference, we will denote the value of $r$ giving rise to the Borderline Case by $r^{b}$. The determination of $r^{b}$ in reference to the factor-price frontier is depicted in Figure 6.

\section{Figure 6. Three Different Cases}

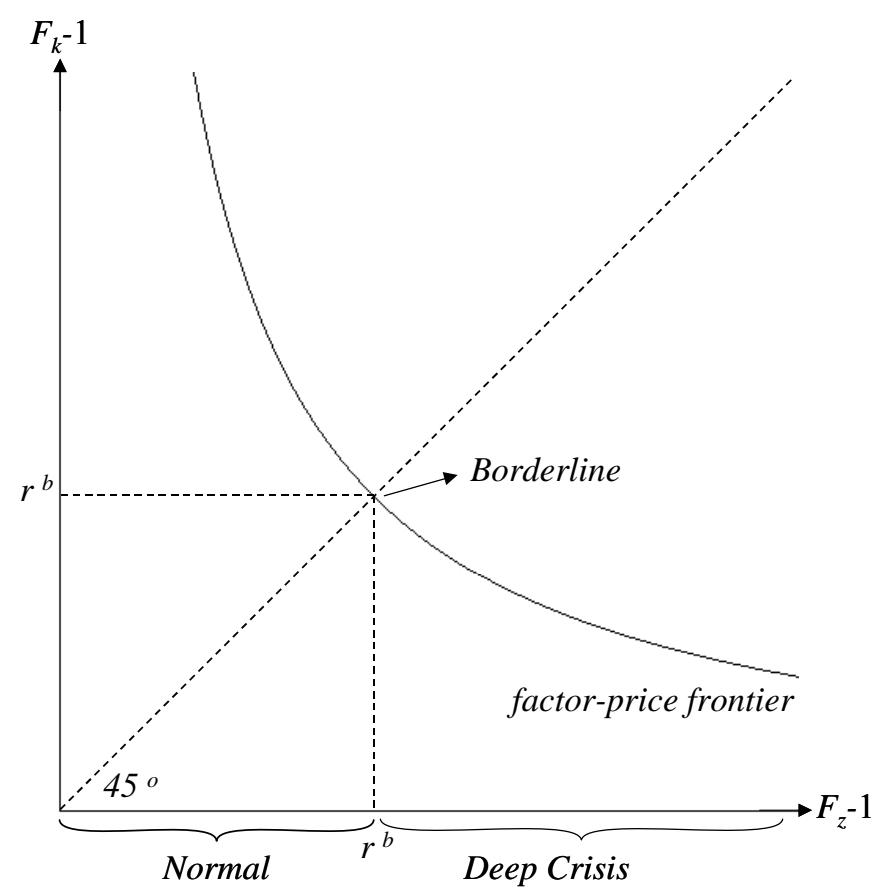

Normal Case. This corresponds to a situation in which firms, if allowed, would like to borrow in order to accumulate physical capital $K$, implying that $B>0, \xi=0, Z=B$, and $\gamma$ $>0$. In words, inventory accumulation would be fully financed by bank credit and, if possible, firms would like to borrow more in order to accumulate physical capital (which the model does not allow). We call this the Normal Case because we envision firms in EMs as being, in principle, highly profitable, to the extent that firms would like to finance their capital accumulation on bank loans, despite the fact that bank loans could be very expensive. A possible reason why firms end up relying so heavily on their own resources is poor credit-market institutions implying, more specifically, poor creditors' protection (see IPES 2005). 
By (6) and (7), it readily follows that

$$
F_{K}(K, Z)-(1+r)=\gamma>0,
$$

and,

$$
F_{Z}(K, Z)=1+r .
$$

This case is identified in Figure 6 to the left of $r^{b}$. Notice that, by (11), the gross marginal productivity of capital is larger than $(1+r)$, a fact that can be used, as in the borderline case, to show that gross revenue maximization is equivalent to profit maximization (recalling that $r>\rho$ ). Equation (12) is just the same equilibrium condition that prevails in the borderline case discussed above (recall equation (9)). Moreover, given that inventories are fully financed by bank loans, it follows from equation (1) that the firm will devote its net assets to the accumulation of physical capital. Hence, $K=A$.

We will now sketch out some dynamic considerations, assuming that the oneperiod maximization problem is repeated each period. Once again, let $A$ ' denote "the firm's next-period initial net assets," and, for the sake of concreteness, let us focus on a periods in which $r$ is constant. We will denote by $z$ the inventory/capital ratio, $Z / K$. Linear homogeneity implies, recalling (12), that $z$ is determined once $r$ is known. This implies that firms will expand along a constant inventory/capital ray $z$.

From equation (3), the fact that $B=Z$, and linear homogeneity of $F(K, Z)$, we get

$$
\pi=F_{K}(K, Z) K .
$$

As already noted, firms will employ their entire net assets to accumulate physical capital. Therefore, if "next period capital" is denoted by $K$ ', we have, by (11), (12) and (13), and recalling that $K^{\prime}=A^{\prime}=\pi$ that

$$
K^{\prime}=K(1+r+\gamma)=(1+m p k),
$$


where $m p k$ stands for net Marginal Productivity of Capital. Clearly, $m p k>r$, and due to linear homogeneity, mpk is a negative function of $r$. We will collect the main results in the following Proposition:

Proposition 1. In the Normal case, the gross marginal productivity of capital exceeds the interest rate factor $1+r$ on working capital loans, and the firm's own assets are entirely devoted to physical capital accumulation. Moreover, in periods in which $r$ is constant, output, capital, and inventories will grow at a rate equal to the equilibrium net marginal productivity of capital. The latter is a downward-sloping function of the interest rate on working capital loans.

We will now show that all the main stylized facts highlighted in the previous sections are borne out in the Normal case, if we interpret the Sudden Stop in capital flows shock as a jump in working capital interest rate $r$ to a (temporarily) higher plateau, and assume that the elasticity of substitution between $K$ and $Z$ is less than unity.

An increase in $r$ that keeps firms in the Normal phase implies, by (11), a fall in $Z$, since the inventory/capital ratio must fall, and capital remains the same. This results in a fall in output and the net marginal productivity of capital, mpk. ${ }^{43}$ Afterwards, growth resumes but at a lower rate (recall equation (14)). On the other hand, the investment/output ratio is given by ${ }^{44}$

\footnotetext{
${ }^{43}$ Notice that since a rise in the interest rate for working capital results in lower output, the model helps to capture a situation in which "capacity underutilization" increases during a Sudden Stop episode. Under this optic, capacity underutilization is not a demand-driven phenomenon as in a typical textbook Keynesian model, but it is a result of tighter credit constraints, which would not be there under perfect credit markets. Thus, capacity underutilization, as the term has been loosely used in the text, should be interpreted as being measured relative to a first-best equilibrium (or an equilibrium in which credit market distortions are much less severe).

${ }^{44}$ In the empirical analysis we focus on ratios with respect to GDP. This cannot be replicated here because we are working in terms of a partial equilibrium model. Dividing by the sector's output is an approximation, which would be an exact replica of the empirical analysis if inventories were produced at home and if $(r-\rho) B$ is recorded as part of the value added in the banking sector.
} 


$$
\frac{\pi-K}{F(K, Z)-K}
$$

which would be constant if the flow production function, $F-K$, is Cobb-Douglas.

However, in the more realistic case in which the elasticity of substitution between $K$ and $Z$ is less than unity, a fall in the inventory/capital ratio (associated with a rise in $r$ ) would result in a fall in the share of capital and hence, by (15), in the investment/output ratio. This result is consistent with the empirical observation that the investment/output ratio is lower following a $3 \mathrm{~S}$ collapse.

Finally, the credit/output ratio is given by

$$
\frac{Z}{F(K, Z)-K}=\frac{Z}{F(1, z)-1}
$$

which falls as $z$ contracts (which is in line with the data discussed in previous sections). ${ }^{45}$

There is a technical point that needs to be addressed. By (10) and (14), physical capital and profits grow at the rate mpk $>\rho$ and, therefore, the present discounted net assets, $A$, may not converge if the discount rate is $\rho$, unless, for example, after a given point in time $m p k=\rho$. This is a familiar difficulty in open-economy models, which is usually formally resolved by assuming that eventually price and interest configurations ensure the existence of a stationary steady state (e.g., at the risk of sounding repetitious, that after some point in time mpk $=\rho$ ). Due to the model's linearity and, thus, the bangbang nature of optimal solutions, it can readily be shown that Proposition 1 (above) and 2

\footnotetext{
${ }^{45}$ However, there is a slight difference with the data in that here credit as a share of GDP falls at trough time and it remains lower at the time of full recovery, whereas in the empirical section credit as a share of GDP remains the same on average at trough time, and later declines as GDP recovers.
} 
(below) hold true, as long as price/interest configurations that ensure the existence of present discounted values are exogenous. ${ }^{46} 47$

Deep Crisis Case. It corresponds to the situation in which $r$ rises above the borderline case where no inequality constraint (expression (2)) is binding-resulting in $\gamma=0$, and $\xi$ $>0$. See Figure 6. Thus, by (4),

$$
F_{K}(K, Z)-(1+r)=-\xi<0,
$$

and,

$$
F_{Z}(K, Z)=F_{K}(K, Z)<(1+r)
$$

where the inequality in expression (18) follows from (17). Once again, to ensure that gross revenue maximization is equivalent to next-period net asset maximization, we will focus on the case in which $F_{K}>1+\rho$. Notice that (18) is satisfied in the Borderline Case (dividing equation (9) by equation (8)). This implies (because of linear homogeneity) that the inventory/capital ratio is the same in Deep Crisis as in the Borderline Case. Let $z^{b}$ denote the inventory/capital ratio corresponding to the borderline case. Then, in Deep Crisis,

$$
Z=z^{b} K
$$

In Deep Crisis $B=0$, i.e., there is no bank borrowing. Hence, by equations (1) and (19),

$$
A=K+Z=\left(1+z^{b}\right) K
$$

Hence,

$$
K=\frac{A}{1+z^{b}}<A
$$

\footnotetext{
${ }^{46}$ If, in contrast to the present model, the maximand were not linear in $K$, for example, the level of $K$ would be a factor determining the rate of investment.

47 Alternatively, Proposition 1 would also hold true if it is assumed that beyond a given output scale, the maximand becomes concave in $K$, e.g., because of the existence of a fixed factor.
} 
Contrary to previous cases, the demand for capital is lower than it would be if the firm's available assets were entirely devoted to investment in physical capital. The intuition for this is that, given the high cost of working-capital credit, firms prefer to use their own resources to accumulate inventories. This result is in line with the empirical observation that credit remains constant following $3 \mathrm{~S}$ collapse episodes. Moreover, net output $=$ $F(K, Z)-K=\left[F\left(1, z^{b}\right)-1\right] K<\left[F\left(1, z^{b}\right)-1\right] A$. Thus, the output loss, given by the difference of the last two expressions, is, recalling (21), a constant independent of $r$. This implies that a slight increase of $r$ over the Borderline Case results in a discontinuous output contraction, independently of how small the interest rate hike is. This is a very interesting feature of the model.

What about the investment output ratio? By equation (21) and the fact that $A^{\prime}=$ $\pi$,

$$
K^{\prime}=\frac{\pi}{1+z^{b}} .
$$

Hence, by (21) and (22), the investment/output ratio in Deep Crisis satisfies:

$$
\frac{K^{\prime}-K}{F(K, Z)-K}=\frac{\frac{\pi}{1+z^{b}}-K}{\left[F\left(1, z^{b}\right)-1\right] K}=\frac{\frac{\pi}{A}-1}{F\left(1, z^{b}\right)-1} .
$$

We will now compute the investment/output ratio for de Borderline Case. It should be recalled that in this case inventories are entirely financed by bank loans. Thus, in the Borderline Case the investment/output ratio satisfies:

$$
\frac{\pi-K}{F(K, Z)-K}=\frac{\pi-A}{\left[F\left(1, z^{b}\right)-1\right] A},
$$

which equals expression (23) if the following holds true: If the interest rate on bank loans $r=r^{b}$ (i.e., the Borderline interest rate), then, given $A$, gross revenue $\pi$ is the same as the 
Borderline Case even though inventories are fully financed from own resources. But this is precisely what we proved at the end of the subsection on the Borderline Case.

Moreover, by (23) and recalling that $\pi=\left(1+r^{b}\right) A$, it follows that

$$
\frac{K^{\prime}-K}{F(K, Z)-K}=\frac{r^{b}}{F\left(1, z^{b}\right)-1} \text {. }
$$

The following Proposition collects the central implications of the analysis:

Proposition 2. Firms enter into Deep Crisis as the rate of interest exceeds the level that gives rise to the borderline case (in which no inequality constraint is binding). However, the inventory/capital ratio remains as in the borderline case. In contrast, the demand for working capital credit vanishes, and the demand for capital falls. As a result, output and the credit/output ratio fall. The extent of the discontinuous output fall is independent of how small or how large is the rise in $r$ (in the region in which it is profitable to keep the firm in operation). Moreover, inside the Deep Crisis region, the investment/output ratio is constant and equal to the one prevailing in the Borderline Case.

An implication of the above analysis is that if the economy starts on the Normal Case and $r$ rises above $r^{b}$, output will suffer a strong contraction, bank credit will dry up, and investment as a share of output will fall. These features are very much in line with the empirical evidence summarized above. After the shock, however, output starts to rise to the extent that the shock does not lower the capital rate of return below the deposit interest rate $\rho$-giving rise to a pattern that invites comparison with the proverbial bird. Further Insights from the Model. The model highlights how imperfections in the capital market could open the door to major crises. In the model, firms may borrow short-term 
for projects that would be very costly to discontinue because, for instance, it is not possible to effectively attach loan collaterals. The risk is that the capital market may stop working smoothly (e.g., because of a global financial shock, like the Russian crisis and related events in 1998), resulting in a sharp rise in the interest rate of working capital loans or, more generally, loans that would be very costly to discontinue. ${ }^{48}$ Therefore, in the final analysis, Sudden Stops and Phoenix Miracles may be reflecting fundamental weaknesses in EMs' domestic financial systems, which, combined with global shocks, give rise to major crises.

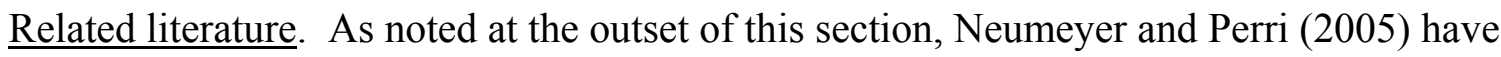
worked out an RBC model that captures some of the flavor of our model. As in our setup, interest rates on working capital loans are assumed exogenous to the model. This is a plausible assumption given the prevalence of factors that are external to EMs, which, among other things, is reflected in a remarkable bunching of crisis episodes. A similar research strategy is followed in Mendoza and Smith (2002), for example, although the exogenous crisis-triggering factors are Sudden Stops.

\section{Summary and Some Implications}

Results in this paper support the view that recent capital-market crises in Emerging Market economies reflect the existence of serious malfunctioning in the financial system (e.g., excessive short-term lending and Liability Dollarization). This makes economies vulnerable to shocks that otherwise would result in mild recessions.

Interestingly, however, output-collapse episodes in EMs show that recovery can be fast and take place without credit in a Phoenix-like fashion. This characteristic is

${ }^{48}$ See Calvo (2005). 
shared by the US Great depression, which also has in common the failure of the domestic banking system, possibly a key feature to explain credit stagnation during the output recovery phase.

Credit-less recovery sounds paradoxical but, upon reflection, it is not. As shown in the model developed in Section IV, an output collapse may be the result of a "liquidity crunch" provoked by a sharp increase in interest rates. Liquidity, however, can be restored by different means, one of which is a discontinuation of investment projects. In this fashion, liquidity and output thus increase, while investment (a key engine of growth under normal circumstances) collapses.

Lowering the rate of investment is not the only way firms could try to offset liquidity crunch. How firms deal with that situation is a research topic on which we know very little. Progress on this account will likely call for detailed microeconomic data and analysis, thus opening a large and exciting research agenda. 


\section{References}

Bernanke, B., 1995, "The Macroeconomics of the Great Depression: A Comparative Approach," Journal of Money, Credit and Banking, Vol. 27, No 1, 1-28.

Calvo, G.A., 1999, “Contagion in Emerging Markets: When Wall Street is a Carrier” in Calvo (2005).

Calvo, G.A., 2005, Emerging Capital Markets in Turmoil: Bad Luck or Bad Policy?, MIT Press, Cambridge, MA.

Calvo, G.A., Izquierdo A., and Talvi E., 2003, "Sudden Stops, the Real Exchange Rate and Fiscal Sustainability: Argentina's Lessons", in Alexander V., Mélitz J., von Furstenberg G.M. (Eds.), Monetary Unions and Hard Pegs; Oxford University Press, Oxford, UK, pp. 150--181. Also in Calvo (2005).

Calvo, G. A., Izquierdo, A., and Mejía, L.F., 2004, “On the Empirics of Sudden Stops: The Relevance of Balance-Sheet Effects” NBER Working Paper 10520.

Calvo, G. A., and Talvi, E., 2005, "Sudden Stop, Financial Factors and Economic Collapse in Latin America: Learning from Argentina and Chile” NBER Working Paper 11153.

Calvo, G. A., Izquierdo A., and Loo-Kung R., 2005, "Relative Price Volatility under Sudden Stops: The Relevance of Balance-Sheet Effects" NBER Working Paper 11492, forthcoming in Journal of International Economics.

Caprio, J., and D. Klingebiel, 2003. "Episodes of Systemic and Borderline Financial Crises", World Bank.

Cerra, V., and Chaman Saxena, S., 2005, "Growth Dynamics: The Myth of Economic Recovery", IMF Working Paper WP/05/147.

Cole, H., and L. Ohanian, 1999, "The Great Depression in the United States from a Neoclassical Perspective”, Federal Reserve Bank of Minneapolis Quarterly Review, vol 23, No 1, pp. 2-24.

Eichengreen, B., R. Hausmann, and U. Panizza, 2005, “The Pain of Original Sin.” In Eichengreen, Barry and Hausmann, Ricardo, eds., Other People's Money: Debt Denomination and Financial Instability in Emerging Market Economies. Chicago: University of Chicago Press. 
Fisher, Irving, 1933, "The Debt-Deflation Theory of Great Depressions," Econometrica, Vol.1, No.4, pp. 337-357.

Frankel, J., E. Cavallo, 2004, “Does Openness to Trade Make Countries More Vulnerable to Sudden Stops, or Less?: Using Gravity to Establish Causality,” NBER Working Paper No. 10957, December.

Friedman, M., and A. Jacobson Schwartz, 1963, A Monetary History of the United States, 1867-1960; Princeton: Princeton University Press.

Hart, O., 1995, Firms, Contracts, and Financial Structures, Oxford University Press.

IPES, 2005, Unlocking Credit: The Quest for Deep and Stable Bank Lending, InterAmerican Development Bank, Economic and Social Progress in Latin America Report. Published by The Johns Hopkins University Press.

Kendrick, J.,1961, Productivity Trends in the United States, National Bureau of Economic Research; Princeton: Princeton University Press.

Mendoza, E., and K. Smith, 2002, "Margin Calls, Trading Costs, and Asset Prices in Emerging Markets: The Financial Mechanics of the 'Sudden Stop' Phenomenon," NBER Working Paper 9286.

Mendoza, E. and C. Bora Durdu (forthcoming), "Are asset price guarantees useful for preventing Sudden Stops?: A quantitative investigation of the globalization hazard-moral hazard tradeoff", Journal of International Economics.

Mitchell, B., 1998, International Historical Statistics: The Americas 1750-1993, Stockton Press.

Nehru, Vikram and Ashok Dhareshwar, 1993, "A New Database of Physical capital Stock: Sources, Methodology and Results", Revista de Análisis Económico 8 (1), pp. 37-59.

Neumeyer, P. A., and F. Perri, 2005, "Business Cycles in Emerging Economies: The Role of Interest Rates" Journal of Monetary Economics, Volume 52, Issue 2, Pages 345-380. 


\section{Appendix Table 1. \\ Episodes of Output Contraction, 1980-2004}

Non-Systemic Episodes

\begin{tabular}{|c|c|c|c|c|c|}
\hline Type & Country & Peak & Trough & Recovery & $\begin{array}{l}\text { Output } \\
\text { Decline }\end{array}$ \\
\hline Mild & Algeria & 1986 & 1988 & 1989 & $-1.69 \%$ \\
\hline Mild & Algeria & 1990 & 1991 & 1992 & $-1.20 \%$ \\
\hline Mild & Algeria & 1992 & 1994 & 1995 & $-2.98 \%$ \\
\hline Collapse & Argentina & 1984 & 1985 & 1987 & $-7.59 \%$ \\
\hline Collapse & Argentina & 1987 & 1990 & 1992 & $-12.02 \%$ \\
\hline Mild & Brazil & 1987 & 1988 & 1989 & $-0.10 \%$ \\
\hline Mild & Brazil & 1989 & 1990 & 1991 & $-4.30 \%$ \\
\hline Mild & Brazil & 1991 & 1992 & 1993 & $-0.50 \%$ \\
\hline Mild & Brazil & 2002 & 2003 & 2004 & $-0.20 \%$ \\
\hline Collapse & Bulgaria & 1988 & 1993 & 1995 & $-26.49 \%$ \\
\hline Collapse & Bulgaria & 1995 & 1997 & 2002 & $-14.47 \%$ \\
\hline Collapse & Côte d'Ivoire & 2001 & 2004 & - & $-6.18 \%$ \\
\hline Mild & Côte d'Ivoire & 1986 & 1987 & 1988 & $-0.35 \%$ \\
\hline Mild & Côte d'Ivoire & 1989 & 1990 & 1991 & $-1.10 \%$ \\
\hline Mild & Côte d'Ivoire & 1991 & 1993 & 1994 & $-0.44 \%$ \\
\hline Mild & Côte d'Ivoire & 1999 & 2000 & 2001 & $-2.27 \%$ \\
\hline Collapse & Croatia & 1990 & 1993 & 2004 & $-35.92 \%$ \\
\hline Collapse & Czech Republic & 1990 & 1992 & 2000 & $-12.07 \%$ \\
\hline Collapse & Dominican Republic & 1989 & 1990 & 1992 & $-5.83 \%$ \\
\hline Mild & Dominican Republic & 2002 & 2003 & 2004 & $-0.40 \%$ \\
\hline Mild & Ecuador & 1986 & 1987 & 1988 & $-2.15 \%$ \\
\hline Collapse & Hungary & 1989 & 1993 & 2000 & $-18.05 \%$ \\
\hline Mild & Hungary & 1984 & 1985 & 1986 & $-0.25 \%$ \\
\hline Mild & Hungary & 1987 & 1988 & 1989 & $-0.07 \%$ \\
\hline Collapse & Lebanon & 1988 & 1989 & 1991 & $-42.45 \%$ \\
\hline Mild & Malaysia & 1984 & 1985 & 1986 & $-1.12 \%$ \\
\hline Mild & Mexico & 1985 & 1986 & 1989 & $-3.75 \%$ \\
\hline Mild & Mexico & 2000 & 2001 & 2002 & $-0.12 \%$ \\
\hline Collapse & Morocco & 1991 & 1993 & 1994 & $-5.00 \%$ \\
\hline Mild & Morocco & 1986 & 1987 & 1988 & $-2.54 \%$ \\
\hline Mild & Morocco & 1998 & 1999 & 2000 & $-0.08 \%$ \\
\hline Collapse & Panama & 1982 & 1983 & 1985 & $-4.49 \%$ \\
\hline Collapse & Panama & 1986 & 1988 & 1991 & $-14.95 \%$ \\
\hline Collapse & Peru & 1987 & 1990 & 1996 & $-23.53 \%$ \\
\hline Collapse & Philippines & 1983 & 1985 & 1989 & $-14.10 \%$ \\
\hline Mild & Philippines & 1990 & 1991 & 1993 & $-0.58 \%$ \\
\hline Collapse & Poland & 1990 & 1991 & 1994 & $-7.01 \%$ \\
\hline Collapse & Russia & 1989 & 1996 & 1997 & $-41.91 \%$ \\
\hline Mild & South Africa & 1984 & 1985 & 1988 & $-4.00 \%$ \\
\hline Mild & South Africa & 1989 & 1992 & 1994 & $-3.44 \%$ \\
\hline Mild & Tunisia & 1985 & 1986 & 1987 & $-1.45 \%$ \\
\hline Collapse & Turkey & 2000 & 2001 & 2003 & $-7.49 \%$ \\
\hline Collapse & Ukraine & 1989 & 1999 & 2004 & $-61.59 \%$ \\
\hline Collapse & Uruguay & 1998 & 2002 & 2004 & $-17.69 \%$ \\
\hline Mild & Uruguay & 1994 & 1995 & 1996 & $-1.45 \%$ \\
\hline Collapse & Venezuela, Rep. Bol. & 1988 & 1989 & 1991 & $-8.57 \%$ \\
\hline Collapse & Venezuela, Rep. Bol. & 1998 & 1999 & 2001 & $-6.09 \%$ \\
\hline Collapse & Venezuela, Rep. Bol. & 2001 & 2003 & 2004 & $-15.91 \%$ \\
\hline Mild & Venezuela, Rep. Bol. & 1993 & 1994 & 1995 & $-2.35 \%$ \\
\hline Mild & Venezuela, Rep. Bol. & 1995 & 1996 & 1997 & $-0.19 \%$ \\
\hline
\end{tabular}

3S Episodes

\begin{tabular}{lllccc}
\hline \multicolumn{1}{c}{ Type } & \multicolumn{1}{c}{ Country } & Peak & Trough & Recovery & $\begin{array}{c}\text { Output } \\
\text { Decline }\end{array}$ \\
\hline Collapse & Argentina & 1980 & 1982 & 1984 & $-10.36 \%$ \\
Collapse & Argentina & 1998 & 2002 & 2004 & $-18.36 \%$ \\
Mild & Argentina & 1994 & 1995 & 1996 & $-2.85 \%$ \\
Collapse & Brazil & 1980 & 1983 & 1985 & $-7.12 \%$ \\
Collapse & Chile & 1981 & 1983 & 1986 & $-13.72 \%$ \\
Mild & Chile & 1998 & 1999 & 2000 & $-1.14 \%$ \\
Mild & Colombia & 1998 & 1999 & 2002 & $-4.20 \%$ \\
Collapse & Côte d'Ivoire & 1982 & 1984 & 1986 & $-6.50 \%$ \\
Collapse & Ecuador & 1998 & 1999 & 2001 & $-6.30 \%$ \\
Mild & Ecuador & 1981 & 1983 & 1984 & $-3.09 \%$ \\
Collapse & El Salvador & 1980 & 1982 & 1992 & $-16.10 \%$ \\
Collapse & Indonesia & 1997 & 1998 & 2003 & $-13.13 \%$ \\
Mild & Lebanon & 1999 & 2000 & 2001 & $-0.50 \%$ \\
Collapse & Malaysia & 1997 & 1998 & 2000 & $-7.36 \%$ \\
Collapse & Mexico & 1981 & 1983 & 1985 & $-4.80 \%$ \\
Collapse & Mexico & 1994 & 1995 & 1997 & $-6.17 \%$ \\
Collapse & Morocco & 1994 & 1995 & 1996 & $-6.58 \%$ \\
Mild & Morocco & 1980 & 1981 & 1982 & $-2.76 \%$ \\
Mild & Morocco & 1982 & 1983 & 1984 & $-0.56 \%$ \\
Mild & Morocco & 1996 & 1997 & 1998 & $-2.23 \%$ \\
Collapse & Nigeria & 1980 & 1984 & 1989 & $-21.88 \%$ \\
Collapse & Peru & 1981 & 1983 & 1986 & $-12.33 \%$ \\
Mild & Peru & 1997 & 1998 & 1999 & $-0.65 \%$ \\
Mild & Philippines & 1997 & 1998 & 1999 & $-0.58 \%$ \\
Collapse & Russia & 1997 & 1998 & 1999 & $-5.30 \%$ \\
Collapse & South Africa & 1981 & 1983 & 1984 & $-6.07 \%$ \\
Collapse & South Korea & 1997 & 1998 & 1999 & $-6.85 \%$ \\
Collapse & Thailand & 1996 & 1998 & 2002 & $-11.74 \%$ \\
Mild & Tunisia & 1981 & 1982 & 1983 & $-0.49 \%$ \\
Collapse & Turkey & 1993 & 1994 & 1995 & $-5.46 \%$ \\
Collapse & Turkey & 1998 & 1999 & 2000 & $-4.71 \%$ \\
Collapse & Uruguay & 1981 & 1984 & 1991 & $-19.95 \%$ \\
Collapse & Venezuela, Rep. Bol. & 1980 & 1983 & 1986 & $-6.10 \%$ \\
\hline
\end{tabular}


Appendix Table 2.

3S Collapse Episodes

\begin{tabular}{lcccc}
\hline Country & Peak & Trough & Recovery & $\begin{array}{c}\text { Output } \\
\text { Decline }\end{array}$ \\
\hline Argentina & 1980 & 1982 & 1984 & $-10.36 \%$ \\
Argentina & 1998 & 2002 & 2004 & $-18.36 \%$ \\
Brazil & 1980 & 1983 & 1985 & $-7.12 \%$ \\
Chile & 1981 & 1983 & 1986 & $-13.72 \%$ \\
Côte d'Ivoire & 1982 & 1984 & 1986 & $-6.50 \%$ \\
Ecuador & 1998 & 1999 & 2001 & $-6.30 \%$ \\
El Salvador & 1980 & 1982 & 1992 & $-16.10 \%$ \\
Indonesia & 1997 & 1998 & 2003 & $-13.13 \%$ \\
Malaysia & 1997 & 1998 & 2000 & $-7.36 \%$ \\
Mexico & 1981 & 1983 & 1985 & $-4.80 \%$ \\
Mexico & 1994 & 1995 & 1997 & $-6.17 \%$ \\
Morocco & 1994 & 1995 & 1996 & $-6.58 \%$ \\
Nigeria & 1980 & 1984 & 1989 & $-21.88 \%$ \\
Peru & 1981 & 1983 & 1986 & $-12.33 \%$ \\
Russia & 1997 & 1998 & 1999 & $-5.30 \%$ \\
South Africa & 1981 & 1983 & 1984 & $-6.07 \%$ \\
South Korea & 1997 & 1998 & 1999 & $-6.85 \%$ \\
Thailand & 1996 & 1998 & 2002 & $-11.74 \%$ \\
Turkey & 1993 & 1994 & 1995 & $-5.46 \%$ \\
Turkey & 1998 & 1999 & 2000 & $-4.71 \%$ \\
Uruguay & 1981 & 1984 & 1991 & $-19.95 \%$ \\
Venezuela, Rep. Bol. & 1980 & 1983 & 1986 & $-6.10 \%$ \\
\hline
\end{tabular}




\section{Data Appendix}

Our sample of EMs is composed of those countries tracked by JP Morgan to construct its global Emerging Market Bond Index. The complete list of EMs includes Algeria, Argentina, Brazil, Bulgaria, Côte d'Ivoire, Chile, Colombia, Croatia, Czech Republic, Dominican Republic, Ecuador, El Salvador, Hungary, Indonesia, Lebanon, Malaysia, Mexico, Morocco, Nigeria, Panama, Peru, Philippines, Poland, Russia, South Africa, South Korea, Thailand, Tunisia, Turkey, Ukraine, Uruguay, and Venezuela. Data is collected on an annual basis unless otherwise stated. Data on nominal GDP, real GDP and investment for the US Great Depression comes from the Bureau of Economic Analysis. Credit, nominal wages, producer price index, nominal exchange rate (vis-à-vis gold), and real exchange rate (vis-à-vis Pound) comes from NBER's Macro-history database. Data on employment and the capital stock come from Kendrick (1961), and data on the current account balance is from Mitchell (1998).

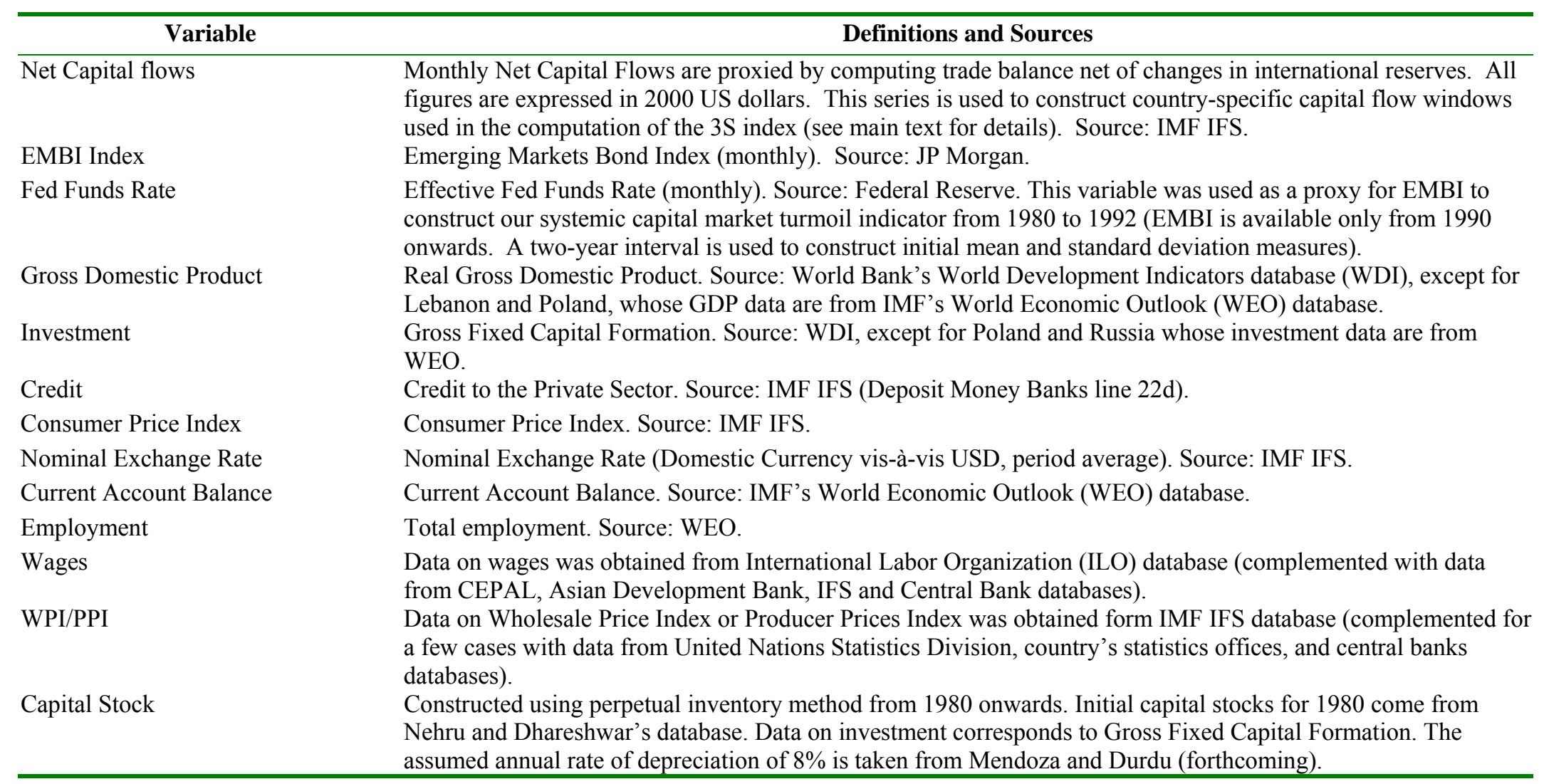




\section{Appendix 1 - Mild Recessions vs. Output Collapses}

One may ask whether the Phoenix Miracle occurs only in episodes displaying output collapse. For this reason, we compare $3 \mathrm{~S}$ output collapses with $3 \mathrm{~S}$ mild recessions (i.e., 3S episodes with cumulative contractions in output smaller than the median contraction). This leaves us with 22 output collapse episodes and 11 mild recession episodes. Given the small number of mild episodes, we interpret these differences with caution. Under this new classification, the salient features that seem to separate collapses from mild recessions in terms of Phoenix Miracle characteristics are as follows (see Table 3 for point estimates and tests):

- There seems to be no clear difference in domestic credit to the private sector as a share of GDP between pre-crisis peak and full recovery points for mild recessions, an element that, as previously stated, does come out distinctively for collapses. This suggests that expansions following mild recessions are likely to take place with increases in credit, a feature that differs from the "credit-less" recoveries that embody Phoenix Miracles.

- In terms of external financing, there seems to be more dispersion across mild recessions. Although the coefficient indicating differences from pre-crisis peak to full-time recovery time in the current account balance measured in points of GDP is 2.7, it is not significant at the 10 percent level, yet another difference with collapses (where differences in the current account balance are much larger and statistically significant).

It is also worth highlighting that, in contrast to mild recessions, $3 \mathrm{~S}$ collapse episodes fully pass tests bank credit and current account balance differences, representing 
the quintessence of Phoenix Miracles. Moreover, they account for two-thirds of the number of $3 \mathrm{~S}$ contraction episodes analyzed here (22 cases out of 33$)$, with an average output collapse of almost 10 percent. $^{49}$ This fact points to the relevance of $3 \mathrm{~S}$ events in the behavior of output in EMs.

Table 3. Mild Recession Episodes: Average Differences along Pre-crisis peaks, Troughs, and Full Recovery Points

\begin{tabular}{|c|c|c|c|}
\hline & Peak to Through & $\begin{array}{l}\text { Trough to } \\
\text { Recovery }\end{array}$ & $\begin{array}{c}\text { Peak To } \\
\text { Recovery }\end{array}$ \\
\hline \multirow[t]{3}{*}{ Credit/GDP } & -0.317 & -2.624 & -2.008 \\
\hline & [ 4.723] & {$[2.212]$} & {$[6.145]$} \\
\hline & 11 & 11 & 11 \\
\hline \multirow[t]{3}{*}{ Current Account Balance/GDP } & $2.405^{*}$ & 0.287 & 2.692 \\
\hline & [ 1.217$]$ & {$[0.816]$} & [ 1.487$]$ \\
\hline & 11 & 11 & 11 \\
\hline
\end{tabular}

49 This contrasts with non-systemic episodes in our sample of contractions, where only 38 percent come along with collapses in output. 